\title{
, nex \\ Deposition of Biocompatible Polymers by 3D Printing (FDM) on Titanium Alloy
}

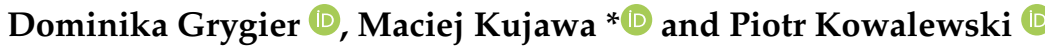

Citation: Grygier, D.; Kujawa, M.; Kowalewski, P. Deposition of Biocompatible Polymers by 3D Printing (FDM) on Titanium Alloy. Polymers 2022, 14, 235. https:// doi.org/10.3390/polym14020235

Academic Editor: Ivan Gitsov

Received: 24 November 2021

Accepted: 5 January 2022

Published: 7 January 2022

Publisher's Note: MDPI stays neutral with regard to jurisdictional claims in published maps and institutional affiliations.

Copyright: (C) 2022 by the authors. Licensee MDPI, Basel, Switzerland. This article is an open access article distributed under the terms and conditions of the Creative Commons Attribution (CC BY) license (https:// creativecommons.org/licenses/by/ $4.0 /)$.
Faculty of Mechanical Engineering, Wroclaw University of Science and Technology, Wybrzeże Stanisława Wyspiańskiego 27, 50-370 Wrocław, Poland; dominika.grygier@pwr.edu.pl (D.G.); piotr.kowalewski@pwr.edu.pl (P.K.)

* Correspondence: maciej.kujawa@pwr.edu.pl

\begin{abstract}
Nowadays, the replacement of a hip joint is a standard surgical procedure. However, researchers have continuingly been trying to upgrade endoprostheses and make them more similar to natural joints. The use of 3D printing could be helpful in such cases, since 3D-printed elements could mimic the natural lubrication mechanism of the meniscus. In this paper, we propose a method to deposit plastics directly on titanium alloy using 3D printing (FDM). This procedure allows one to obtain endoprostheses that are more similar to natural joints, easier to manufacture and have fewer components. During the research, biocompatible polymers suitable for 3D FDM printing were used, namely polylactide (PLA) and polyamide (PA). The research included tensile and shear tests of metal-polymer bonds, friction coefficient measurements and microscopic observations. The friction coefficient measurements revealed that only PA was promising for endoprostheses (the friction coefficient for PLA was too high). The strength tests and microscopic observations showed that PLA and PA deposition by 3D FDM printing directly on Ti6Al4V titanium alloy is possible; however, the achieved bonding strength and repeatability of the process were unsatisfactory. Nevertheless, the benefits arising from application of this method mean that it is worthwhile to continue working on this issue.
\end{abstract}

Keywords: FFF; PLA; PA; Ti-6Al-4V; friction; adhesion

\section{Introduction}

The replacement of a hip joint after osteoarthritis or fracture is nowadays a standard surgical procedure performed worldwide [1]. Despite this, there is an ongoing effort to improve the currently used hip endoprosthesis [2-5]. Researchers focus on creating endoprostheses that are structurally similar to the natural joint [6].

Sonntag et al. distinguished four approaches to the development of new endoprostheses [7]:

(a) The introduction of new materials;

(b) The application of a coating;

(c) The modifcation of the surface layer;

(d) The use of "soft" sliding materials.

The usage of "soft" sliding materials is the closest to a natural joint, where there is a soft tissue covering. Moreover, the use of "soft" sliding materials results in lower friction resistance and higher durability than with classic "hard" materials used in endoprostheses. The role of "soft" materials in the implant is fulfilled by plastics.

Recently, the popularity of 3D printing has significantly increased, meaning there is another technology for processing plastics. Additionally, 3D printing is also used in medicine. Most of the prints are less responsible elements such as models and surgical templates, although various types of implants are also printed [8-10]. Moreover, 3D printing provides the possibility to obtain personalized implants, which are mainly used 
during the replacement of bone defects, e.g., of the craniofacial region after injuries [11]. Additionally, 3D printing allows the reconstruction of the patient's entire bone, e.g., the collarbone or the scapula, when the bone is attacked by cancer and requires complete removal [12]. Printed endoprostheses with individualized geometries are also used in challenging cases [13]. Ji and Guo described a case in which tumor removal required resection of a large portion of the pelvis and the entire hip joint [14]. The creation of a custom endoprosthesis made by $3 \mathrm{D}$ printing allowed for a more favourable solution for the patient. The authors of another paper indicated that by using 3D printing, the stiffness of the endoprosthesis can be adjusted to the stiffness of the bone tissue [15].

The 3D FDM prints are mainly tested for their mechanical properties [16-19]. However, papers analyzing the tribological properties of FDM 3D prints are appearing more frequently [20-25]. The influence of additives on the tribological properties of 3D prints has also been described [25-28]. Researchers have focused on the use of 3D prints in elements of machines. The tribological properties of FDM 3D prints intended for implant elements have rarely been discussed in the literature. This is due to the fact that such elements must be made of biocompatible plastics, and there are few biocompatible materials among those used in FDM 3D printing [29-31]. Moreover, the examinations must be performed in the presence of a medium that imitates synovial fluid, which is an additional complication [32-34].

Little information has been found on the 3D printing of sliding parts of endoprostheses using "soft" materials. Nevertheless, the published results encourage research to be conducted on this issue. Researchers have indicated that 3D prints are characterized by better tribological properties than parts produced by other methods. Borges et al. [35] compared the tribological properties of injected PCU (polycarbonate urethane) with that obtained by 3D FDM printing. Tribological investigations were conducted in the presence of fetal bovine serum. The printed samples exhibited $27 \%$ less wear than the injection-molded samples. The authors indicated that the printed specimens had higher porosity, meaning the serum was better absorbed. Therefore, the printed specimens acted similarly to the natural lubrication mechanism of the meniscus. The porosity of FDM prints has been studied by other authors, although in the context of mechanical properties rather than tribological properties [36-38]. Moreover, the porosity of 3D prints is seen as a great chance to produce scaffolds that promote tissue growth [39-41]. In terms of silicone (a material from a different group of plastics), no significant differences were found between the properties of a 3D printout and the sample manufactured by injection molding. In the mentioned studies, the tribological properties were not tested, although the absorption of water was examined and no significant differences were found [42].

"Soft" materials cannot be applied for the entire implant. They ought to work together with high-strength materials, since the implant needs to be fastened in the bone. As a result, implants consist of a metal core and a plastic "cap" that works frictionally with the metal. The plastic component must be bonded to the metal without the use of glue, since this kind of a substance could have a negative effect on the patient's body. Consequently, the plastic components are attached to the metal ones using screws, bolts, or shaped connections (e.g., groove with wedge).

Metal-polymer combinations occur most frequently in automotive and aerospace applications. Most of the metal-polymer compositions used today are composites, for which the shape of the metal and polymer phases is random and the size of individual phases is in the nano- or micrometer range [43]. However, hybrid materials are also encountered. They show a clear distinction between the polymeric and metallic phases on the macroscale. Problem occur during the forming process of such hybrids, because both materials exhibit completely different mechanical properties [44,45]. The formation of such joints is based mainly on the mechanical "hooking" of metal elements in polymers; however, a method based on the formation of adhesive joints using increased temperature and pressure is also used [46-50]. 
There are proposals to use 3D FDM printing to create metal-polymer joints, although they are based on 3D printing by applying polymers to polymers, thereby creating a rivet that holds the metal part [51]. Other additive manufacturing methods were used to create the surface shape of the metallic material to enhance the bonding force [52]. No papers have been found describing the direct application of plastic to metal by 3D FDM printing.

When the plastic part is made using 3D printing, the plastic can be applied directly to the metal. This would simplify the manufacturing process and minimize the number of components used in the endoprosthesis. In addition, literature reports indicate that printed samples experience 27\% less wear than injection molded samples [35]; thus, if 3D printing was used in endoprostheses, less wear could be expected (longer life of the component).

For these reasons, we decided to conduct research on 3D printing using FDM method on titanium alloy surfaces. Additionally, friction coefficients of plastic-titanium alloys were measured for cases of dry friction and in the presence of a lubricant.

\section{Materials and Methods}

The purpose of this study was to determine if it is possible to achieve a permanent plastic-to-metal bond by applying liquid plastic directly to metal using 3D FDM printing. Additionally, it was checked whether such applied 3D prints have a sufficiently low coefficient of friction to be used in endoprostheses. In order to carry out the research, it was necessary to decide which 3D printing method has the potential to apply plastic to metal. Moreover, the components consisting of plastic and metal are planned to be used in endoprostheses. Therefore, both the metallic material and plastic ought to be able to be applied in the human body. For this reason, the materials selected for the research had to be selected taking into account specific criteria, such as the biocompatibility. The deposition of plastics to metals by 3D printing is not yet practiced in research or industrial processes; therefore, a method for carrying out such an operation had to be developed. Moreover, the 3D printer needed to be adapted to this task. Appropriate adaptation was also required for the test stand, which was used to check the friction in the printed polymer-metal pair and the shear and tearing forces of the printed polymer-metal bond.

Summing up, preparation for the research included the following steps:

(a) Selection of 3D printing method;

(b) Selection of metallic material;

(c) Selection of biocompatible polymers;

(d) Development of a method for application of a thermoplastic polymer to metal;

(e) Adaptation of a 3D printer for application of a thermoplastic polymer to metal;

(f) Preparation of the test stand to measure the destructive forces of polymer-metal bonds.

This chapter describes in detail the preparation steps mentioned above.

\subsection{D Printing Method}

Currently, more than ten 3D printing methods can be distinguished [53]. The most important of these methods are:

- FDM (fused deposition modeling);

- SLA (stereolithography);

- SLS/SLM (selective laser sintering/selective laser melting);

- EBM (electron beam melting).

FDM is based on the deposition of molten material. Layer-by-layer the device applies a heated thermoplastic polymer, which cools down and hardens. In the SLA method, a photosensitive resin is used, which is hardened by laser light. The other methods use a material in the form of a powder, with differences in the way the grains are fused. In SLS, the grains are sintered together by laser, while in SLM the powder is completely melted and solidifies after cooling. In the case of EBM, the melting is achieved using an electron beam.

Among the mentioned 3D printing methods, the FDM method is currently the most widespread, since it requires the least complicated and consequently the cheapest equip- 
ment [54]. In order to make the results useful to more 3D printer users, it was decided to use the FDM method to attempt to make prints on metal.

\subsection{Metallic Material}

Among all metallic biomaterials, titanium and its alloys are currently the best materials for various types of implants. Titanium has fine mechanical properties and very good corrosion resistance and biocompatibility. Additionally, it has the lowest specific gravity and Young's modulus as compared to austenitic steels and cobalt alloys. The very good biotolerance of titanium in the environments of living organisms causes the occurrence of the process of osteointegration (fusion of bone tissue with the titanium surface of the implant). This element has a high affinity for oxygen, thanks to which a passive layer of $\mathrm{TiO}_{2}$ easily forms on its surface, protecting it against corrosion. Due to the complex manufacturing processes, making an implant from a titanium alloy is associated with high costs.

The classification of titanium alloys is based on the structural criterion in the equilibrium state. Pure titanium exists in two allotropic varieties: $\alpha$ (at transformation temperatures lower than $882{ }^{\circ} \mathrm{C}$ ) and $\beta$ (at transformation temperatures higher than $882{ }^{\circ} \mathrm{C}$ ). By adding alloying additives and using appropriately selected thermomechanical processes, titanium alloys used in bioengineering can be divided into three groups: single-phase $\alpha$ alloys, dual-phase $\alpha+\beta$ alloys and single-phase $\beta$ alloys.

The metal on which the plastic was printed was titanium alloy Ti6Al4V. It is one of the most popular metals used in orthopaedic synovial joint replacements (knee or hip joints), as it is characterized by low density, high strength, superior corrosion resistance and excellent biocompatibility [55]. It is a two-phase titanium alloy, with aluminium strengthening the $\alpha$ phase and reducing the density of the alloy and vanadium stabilizing the $\beta$ phase. The tensile strength of the alloy is about $860 \mathrm{MPa}$ and the yield strength is about $780 \mathrm{MPa}$. The elongation ought to be within $10 \%$. Heat treatments such as quenching and tempering or supersaturation and ageing can change the phase morphology and increase the mechanical properties.

Titanium alloys are used to produce joint and knee endoprostheses, intramedullary nails, plates, bone screws and various prosthetic products (bridges), and are used in cardiac surgery and surgical cardiology. Ti6Al4V alloy is suitable for processing by 3D EBM printing, and this method is used to make implants for skull reconstruction, among other uses [56-58].

\subsection{Plastic Materials}

A wide range of thermoplastic polymers are used in FDM 3D printing. The group of plastics used in this method contains more than a dozen materials. Moreover, more thermoplastics, as well as composites based on their matrices, are continually proposed for use in 3D FDM printing $[59,60]$. However, we conducted research on the methods used for applying plastic by FDM 3D printing with the intention of using manufactured components in implants. Therefore, the plastic used ought to be biocompatible, which means that it will not have a toxic effect on the human body, will not affect the immune system and will not have a destructive effect on the blood. Only a few of the many materials used in FDM 3D printing are biocompatible, namely polylactide (PLA), polyamide (PA) and polyetheretherketone (PEEK).

PLA is one of the most widely used materials in FDM technology and is used as a biocompatible and biodegradable material introduced into the body [61].

PA is more challenging than the most popular materials used in FDM 3D printing; however, obtaining good quality prints is not as hard as with PEEK. PA filaments are available and manufacturers provide recommended printing process parameters.

PEEK is often used for implants. Such 3D prints made from PEEK replace ribs [62] or serve as vertebral stabilizers in the spine [63]. Additionally, 3D FDM printing with PEEK is possible, although it is a difficult process and requires a printer with above-standard parameters [63]. 
Ultra-high molecular weight polyethylene PE-UHMW is worth mentioning too, since it is a polymer that is widely used in endoprostheses. Due to the fact that it is a thermoplastic, it would seem that it can be used in FDM. Unfortunately, this material is characterized by an almost zero MFI melt flow index, which eliminates the possibility of extruding this material and its use with the FDM method. Only high-density polyethylene PE-HD [62], which is a material from the same group as PE-UHMW (however, with much weaker mechanical properties), can be successfully 3D-printed using FDM. Currently, PE-UHMW is successfully used only with the SLS printing method [64].

No papers regarding the deposition of plastic layers on titanium alloy by FDM printing were found. As a result, no experience from other studies was gathered and work was carried out on the deposition of plastics by 3D printing from the very beginning. Hence, it was decided that the work would begin with tests with PLA and PA, which are materials that are available and unproblematic for FDM 3D printing. PEEK, which is a difficult material for FDM 3D printing, was excluded from this initial stage of research. Positive results from the verification tests would allow the technology for manufacturing metalpolymer components using advanced polymeric materials such as PEEK to be developed in the next stage.

Finally, two materials were used to make the prints: polylactide (PLA) and polyamide (PA). Prints were made on a Zortrax M300 Dual printer. The filaments used were also from the same manufacturer, and their trade names were Z-PLA (polylactide) and Z-Nylon (polyamide). It was decided to use materials from Zortrax, since in FDM the printing process parameters are very important. The printer software has in its database parameters dedicated to these materials, which significantly increases the chances of a successful printing process. Moreover, Zortrax provides test results for their materials, providing the values for their most important properties (Table 1).

Table 1. Properties of Zortrax filaments used in research $[65,66]$.

\begin{tabular}{cccc}
\hline Properties & Test Method & Z-PLA & Z-Nylon \\
\hline Tensile Strength & ISO 527:1998 & $47.95 \mathrm{MPa}$ & $33.22 \mathrm{Mpa}$ \\
\hline Breaking Stress & ISO 527:1998 & $46.53 \mathrm{Mpa}$ & $29.81 \mathrm{Mpa}$ \\
\hline $\begin{array}{c}\text { Elongation at Max } \\
\text { Tensile Stress }\end{array}$ & ISO 527:1998 & $3.80 \%$ & $9.17 \%$ \\
\hline Elongation at Break & ISO 527:1998 & $4.32 \%$ & $23.62 \%$ \\
\hline Bending Stress & ISO 178:2011 & $56.80 \mathrm{Mpa}$ & $38.30 \mathrm{Mpa}$ \\
\hline Flexural Modulus & ISO 178:2011 & $1.47 \mathrm{Gpa}$ & $781.01 \mathrm{Mpa}$ \\
\hline Izod Impact, Notched & ISO 180:2004 & $3.14 \mathrm{~kJ} / \mathrm{m}^{2}$ & $12.81 \mathrm{~kJ} / \mathrm{m}^{2}$ \\
\hline Melt Flow Rate & ISO 1133:2006 & $\begin{array}{c}14.48 \mathrm{~g} / 10 \mathrm{~min} \\
(\mathrm{Load} 2.16 \mathrm{~kg},\end{array}$ & $\begin{array}{c}9.23 \mathrm{~g} / 10 \mathrm{~min} \\
(\mathrm{Load} 5.00 \mathrm{~kg}\end{array}$ \\
\hline Temperature 190 $\left.{ }^{\circ} \mathrm{C}\right)$ & Temperature $\left.235{ }^{\circ} \mathrm{C}\right)$ \\
\hline Shore Hardness (D) & ISO 868:1998 & $1.292 \mathrm{~g} / \mathrm{cm}^{3}$ & $1.027 \mathrm{~g} / \mathrm{cm}^{3}$ \\
\hline
\end{tabular}

\subsection{Surface Roughness}

A very important factor in the formation of plastic-metal bonds is the roughness of the metal surface. An analysis of the influence of surface roughness on the interactions between the bonded surfaces showed two mechanisms of adhesion force formation. These interactions were related to:

- Adhesive interactions;

- Mechanical interactions.

In terms of very smooth surfaces (zone I in Figure 1), adhesion of a polymer surface to the surface of metal element plays the dominating role in the interactions. This results in 
relatively high stress appearing during polymer-metal separation $\left(\sigma_{a}\right)$. The phenomenon of adhesion is an effect of an increase in the actual contact surface, bringing the particles of joined surfaces closer to the range of second-order interactions.

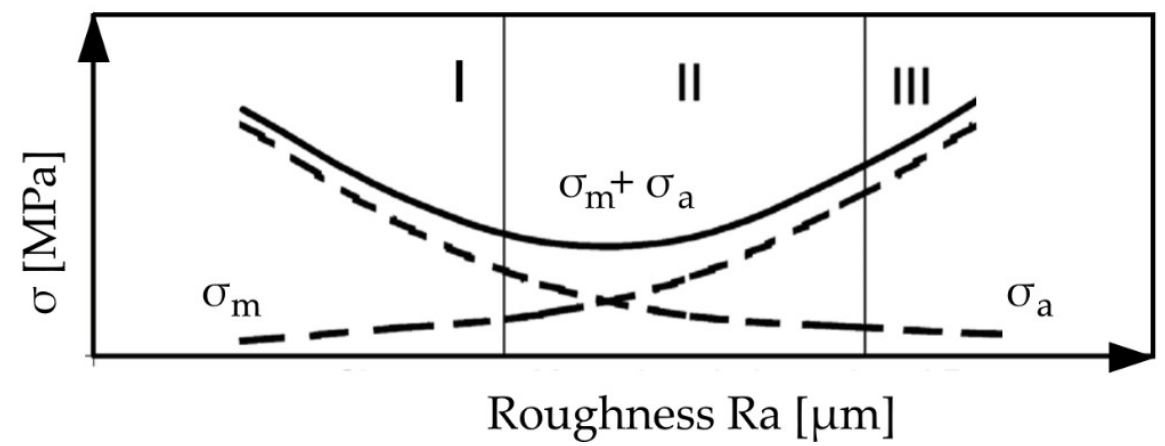

Figure 1. Influence of surface roughness on the failure stress at rupture of a metal-polymer bond.

As the roughness increases, the value of the joining force might decrease (the adhesion decreases-zone II in Figure 1). In terms of large roughness, the mechanical hooking of surfaces increases in its contribution, which increases the stress appearing at the polymermetal separation zone $\left(\sigma_{\mathrm{m}}\right)$ (zone IIII in Figure 1$)$.

The influence of surface roughness on the stress value during the separation of polymer from metal $\left(\sigma_{\mathrm{a}}+\sigma_{\mathrm{m}}\right)$ might occur as shown in Figure 1.

The effect of surface roughness on the bonding strength of metal-polymer components ought to be investigated. Two different surface states are recommended to test metalpolymer components. The surface roughness values of the Ti6Al4V alloy with the following values of the Ra parameter ought to be used:

- $R a<0.5 \mu \mathrm{m}$ (smooth surface);

- $\quad \operatorname{Ra}>5 \mu \mathrm{m}$ (rough surface).

The use of such roughness values will allow one to verify the influence of this parameter on the binding force during the tests. The values of roughness parameters are presented in Table 2. $R_{a}$ is arithmetical mean deviation of the assessed profile. $R_{z}$ is the maximum peak-to-valley height ratio of the profile (within a single sampling length). The value of $\mathrm{Rz}$ is averaged over the assessment length. $\mathrm{R}_{\mathrm{a}}$ and $\mathrm{R}_{\mathrm{z}}$ are the most popular roughness parameters used globally.

Table 2. Roughness parameters for surfaces of selected Ti6Al4V alloy samples.

\begin{tabular}{ccc}
\hline Roughness Parameter & $\begin{array}{c}\text { Value for the Sample with } \\
\text { Lower Roughness }(\boldsymbol{\mu m})\end{array}$ & $\begin{array}{c}\text { Value for the Sample with } \\
\text { Higher Roughness }(\boldsymbol{\mu m})\end{array}$ \\
\hline $\mathrm{R}_{\mathrm{a}}$ & 0.37 & 6.2 \\
$\mathrm{R}_{\mathrm{z}}$ & 2.6 & 36.5 \\
\hline
\end{tabular}

\subsection{Shape of the Bond}

The creation of metal-polymer components by 3D FDM printing can be accomplished in two ways:

(1) The metal component can be placed in the printer workspace under the printer head (Figure 2a). This will allow the printer to apply plastic with standard movements without the danger of collision with the sample;

(2) The printer's nozzle can move next to the sample, meaning a collision with the sample may occur. In this case, it is necessary to develop custom software to determine the movements, so as to avoid collision with the specimen (Figure 2b).

The first case gives the possibility of obtaining components without any changes in software. However, this simplifies the surface-shaping possibilities between the metal and polymer components. 


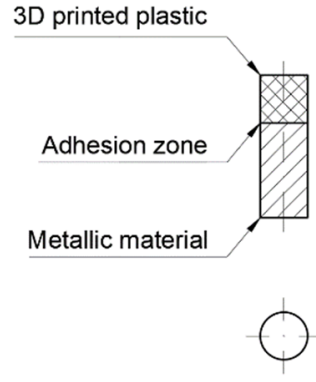

(a)

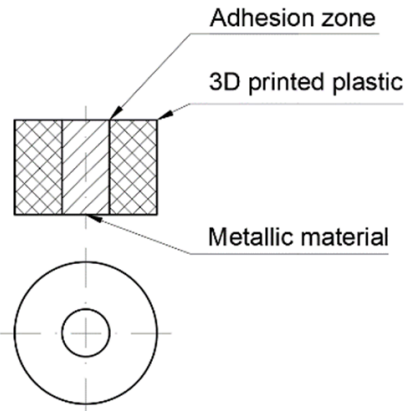

(b)

Figure 2. Geometric variants of the printing of metal-polymer components: (a) printing with a flat surface (simple method); (b) printing with a complex surface (method requiring software modifications).

In the second case, more shapes are possible; thus, not only the adhesion force but also shape connection can be used to obtain the highest possible binding force between two materials. However, this variant requires the development of software by taking into account the presence of the metal component in the working field of the 3D printer. Additionally, 3D printers use various types of software. Some developers make source code available and some do not; thus, not all software can be changed. Therefore, the choice of this option significantly limits the number of end users who can use this method.

The variant shown in Figure 2a was used to produce metal-polymer components. It is less demanding to implement and is based on the use of already existing 3D printers. As a result, it is available to a significantly wider group of 3D printer users.

\subsection{Method of Manufacturing Metal-Polymer Components}

The creation of metal-polymer components by 3D FDM printing can be accomplished in two ways. In the FDM method, the first layer of molten plastic is applied to the printer's bed. In order to achieve successful printing, the material must adhere to the working table throughout the process. After the printing is completed, the finished element must be separated from the table without damaging the machine or the printout. Glass is most often used on the bed, since when it is heated up it keeps the printout on the table and when it is cooled down the printout can be separated from it. We did not manage to find papers describing the application of the material using 3D FDM printers and involving its permanent maintenance on the metal surface, meaning we had to create our own method.

Prints were made using a Zortrax M300 Dual printer. The first attempts at printing consisted of printing a holder for a titanium alloy sample on the printer bed (Figure 3). Most 3D printer control programs allow the user to start depositing plastic at a selected height. In such cases, after entering the height of the sample, the printer will deposit the plastic to the metal without collision.

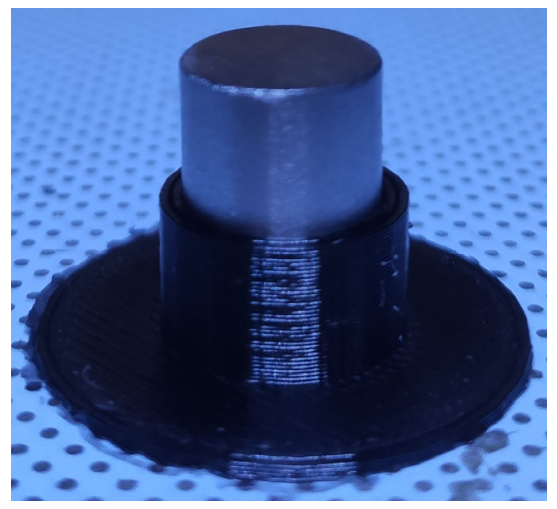

Figure 3. The 3D-printed sample holder that maintained the sample on the heated printer bed. 
The sample was heated using a heated printer bed. The maximum temperature was $100{ }^{\circ} \mathrm{C}$. Unfortunately, attempts to deposit PA and PLA failed-the plastics did not adhere to the titanium alloy. The application of plastic coatings is practiced in the industry (usually where chemical resistance is required). Coatings of this kind usually replace rubber ones because they do not age as quickly. Both the plastic being applied and the metal part must have temperatures above the softening temperature of the plastic. The printer bed could only heat up to $100^{\circ} \mathrm{C}$, meaning an additional heater was required.

An aluminum alloy plate was mounted instead of the printer bed (Figure 4a). A hole was made in the center of the plate where the sample was placed (Figure $4 \mathrm{~b}$ ). The printer was equipped with a capacitive sensor and automatically adjusted the slope of the plate and its distance from the nozzle. Under the plate was a bar on which a heater with a sleeve holding the sample was located (Figure 4c). The aluminum alloy heating block contained the heater and temperature sensor. A sleeve holding the sample and transferring heat to it was placed on the block. A layer of epoxy resin was applied between the aluminum alloy plate and the sleeve to provide insulation and prevent the plate from receiving too much heat from the heater. The heater was controlled using a transistor. This allowed the heating block to be maintained at any temperature up to $260^{\circ} \mathrm{C}$ with an accuracy of $\pm 1{ }^{\circ} \mathrm{C}$. The installation of the additional heater is a low-complexity, low-cost operation that requires components that are easily available.

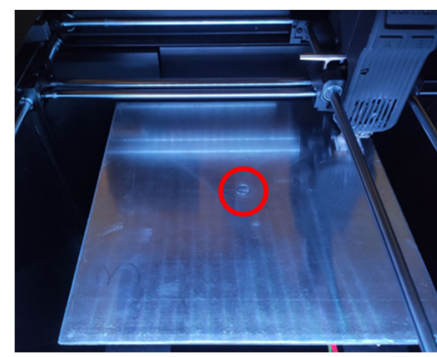

(a)

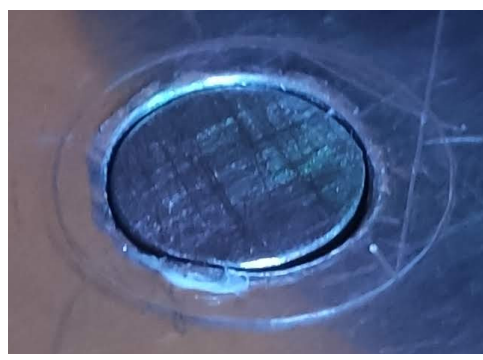

(b)

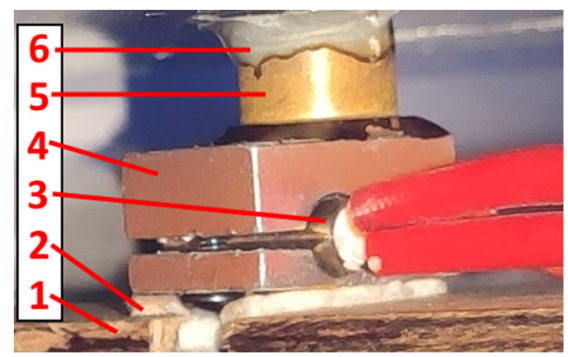

(c)

Figure 4. Replacement of printer bed for heating of a titanium alloy sample to $260{ }^{\circ} \mathrm{C}$ : (a) aluminum alloy plate with a centrally located sample hole (circled in red); (b) sample placed in the socket; (c) heating system located under the plate: 1-beam fixing the heating system; 2-thermal insulation; 3-heater with temperature sensor; 4-heating block; 5-sleeve fixing the sample; 6-thermal insulation made of epoxy resin.

Maintaining the print on the printer bed is crucial during the FDM process. The authors of this paper conducted research to determine which parameters are important to keep the print on the printer bed [67]. The research showed that increasing the flow of plastic is crucial. This allows the material to be "pushed" into the surface and to better fill its irregularities (Figure 5).

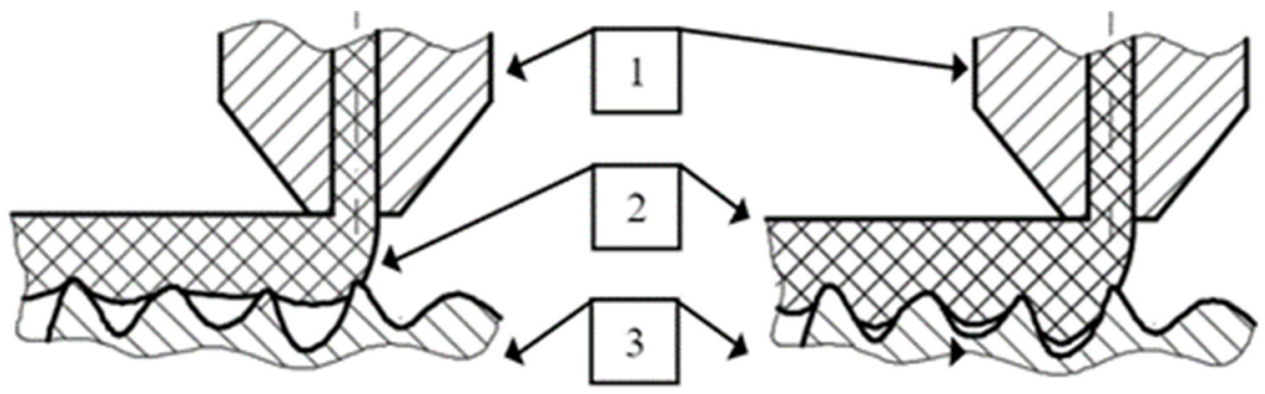

(a)

(b)

Figure 5. Application of the first layer: (a) standard flow; (b) increased flow; 1-printer nozzle; 2-first layer; 3-substrate. 
During attempts to deposit plastic on the titanium alloy, the authors took advantage of the experience from the research mentioned above. Unfortunately, when the flow was increased, the nozzle dragged the material. As a result, the initial layer on the sample surface was uneven and did not cover the entire metal surface (Figure 6a). Significantly better coverage was achieved with the standard flow (Figure 6b). When printing, the parameters recommended by Zortrax obtained from the software database were used. The only change was that the application speed of the first layer was reduced by $50 \%$ to reduce the drag of the plastic.

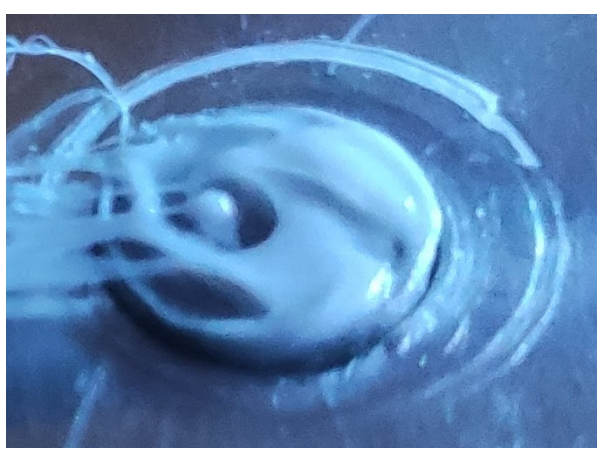

(a)

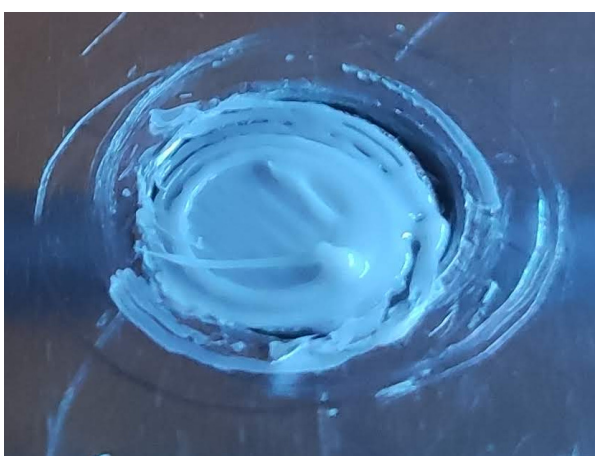

(b)

Figure 6. First layer applied on the titanium alloy sample: (a) increased flow; (b) standard flow.

The samples were heated to a temperature equal to the printer nozzle temperature. The nozzle temperature was given by the material manufacturer. At this temperature, the material has good plasticity. The printing procedure included:

1. De-greasing the sample;

2. Warming up the sample;

3. Applying three layers of plastic;

4. Stopping printing, turning off sample heating and cooling the sample to $60{ }^{\circ} \mathrm{C}$ (PLA) or $160{ }^{\circ} \mathrm{C}$ (PA);

5. Resuming printing.

When the printing was not stopped and the sample was not cooled, the already applied material was too plastic in nature to hold the desired shape (Figure 7a). The nozzle applying the material dragged the plastic, and as a result the print was significantly deformed. Cooling the sample after applying three layers caused better print accuracy (Figure $7 \mathrm{~b}$ ). The printing process took about $12 \mathrm{~min}$ (without waiting for the sample to heat up and then to cool down).

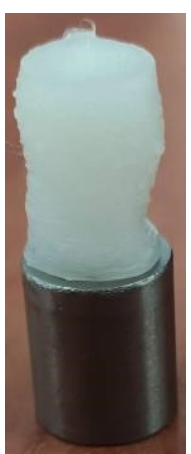

(a)

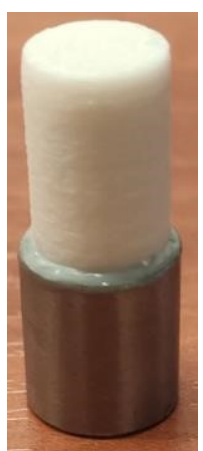

(b)

Figure 7. Obtained prints: (a) deformed PA overprint on a sample that was not cooled down after three layers were applied; (b) correctly printed PLA overprint. 
Researchers agree that the parameters for the 3D FDM printing process have a significant influence on the properties of the printed element [68-73]. Due to the fact that the print parameters are crucial, the parameters used for depositing plastics with 3D FDM printing to metal are presented in Table 3.

Table 3. Manufacturing parameters for 3D-printed samples.

\begin{tabular}{|c|c|c|}
\hline Deposited Plastic & PLA & PA \\
\hline Metal on which plastic is deposited & \multicolumn{2}{|c|}{ Ti6Al4V titanium alloy } \\
\hline $\begin{array}{l}\text { Metal temperature during deposition of the } \\
\text { first three layers of plastic }\end{array}$ & $220^{\circ} \mathrm{C}$ & $260^{\circ} \mathrm{C}$ \\
\hline $\begin{array}{l}\text { Metal temperature during deposition of the } \\
\text { fourth and subsequent layers of plastic }\end{array}$ & $60{ }^{\circ} \mathrm{C}$ & $160^{\circ} \mathrm{C}$ \\
\hline Temperature of the deposited plastic & $220^{\circ} \mathrm{C}$ & $260^{\circ} \mathrm{C}$ \\
\hline 3D printing nozzle diameter & \multicolumn{2}{|c|}{$0.4 \mathrm{~mm}$} \\
\hline Layer height & \multicolumn{2}{|c|}{$0.2 \mathrm{~mm}$} \\
\hline Infill density and infill pattern & \multicolumn{2}{|c|}{$90 \%$ (the infill lines printed at a $45^{\circ}$ angle) } \\
\hline First layer print speed & \multicolumn{2}{|c|}{ Reduced (50\%) } \\
\hline First layer flow ratio & \multicolumn{2}{|c|}{ Normal (100\%) } \\
\hline First layer density & \multicolumn{2}{|c|}{ Normal $(100 \%)$} \\
\hline
\end{tabular}

\subsection{Testing of Metal-Polymer Bond}

Metal-polymer specimens were subjected to strength and tribological tests. The aim of strength testing was to determine shear and normal stresses causing rupture of the plastic-titanium alloy bond. Tribological investigations provided data on the coefficient of friction for pairs consisting of printed specimens. The results of strength and tribological tests allowed us to determine whether metal-polymer components could be useful in endoprostheses.

Materials applied to various types of substrates (e.g., coatings) are most often tested in accordance with the ISO 4624 standard. The method described in this standard consists of sticking test dollies to the coating and removing them. The use of this method requires a coating with a relatively large surface area. In addition, the coating ought to be removed all around the test dolly before pulling it off.

Increasing the surface area of the deposited material might cause difficulties in the manufacturing of specimens. The metal element required heating during the deposition of plastic. Increasing its surface area would require the use of a heating system with a greater power, which would make it more difficult to maintain a precisely set temperature. Moreover, the coatings turned out to be poorly bonded to the substrate. The need to remove the material around the test dollies would probably detach the coating and make it impossible to test it.

Moreover, the ISO 4624 standard describes the removal of coatings, and when carrying out the shear strength tests, alternative methods (ISO 2407 or ISO 16276-2) ought to be used. Due to the above-mentioned factors, we decided to use our own test stand to detach plastic samples deposited on metal. The test stand described below was inspired by the guidelines from ISO 4624.

\subsubsection{Tensile Strength Tests}

The test stand shown in Figure 8 was used to test the tensile strength of each joint.

One end of the test component sample (1) was rigidly fixed in a drill chuck (3), which was screwed to a force sensor (2). The other end was pulled by a flexible wire attached to a pneumatic cylinder (4). The gradual increase in pneumatic pressure increased the normal stress value in the metal-polymer joint until rupture. The highest stress that was transmitted through the component was taken as the strength of the bond. 


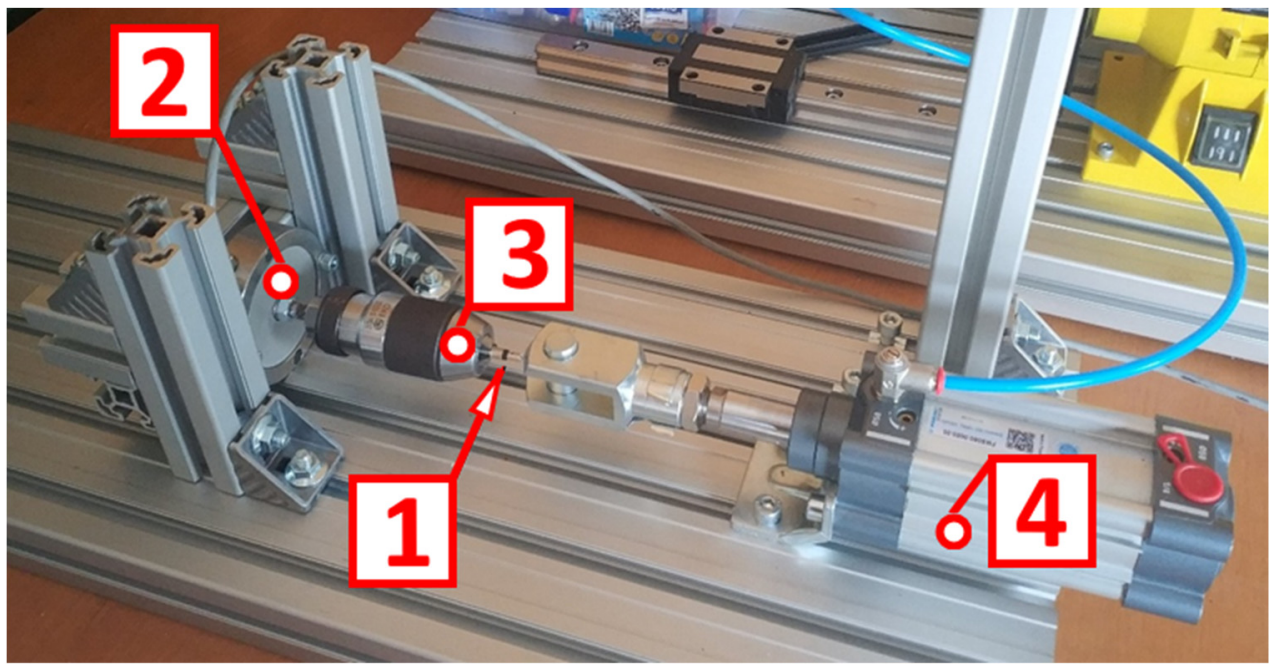

Figure 8. Test stand used to determine the tensile strength of metal-polymer joints: 1 -specimen; 2-force sensor; 3-drill chuck; 4-pneumatic actuator.

\subsubsection{Shear Strength Tests}

A single test stand was used for shear strength determination and tribological testing. For shear strength measurements, a force sensor was mounted on the device to record the shear force value over time. The equipment is shown in Figures 9 and 10.

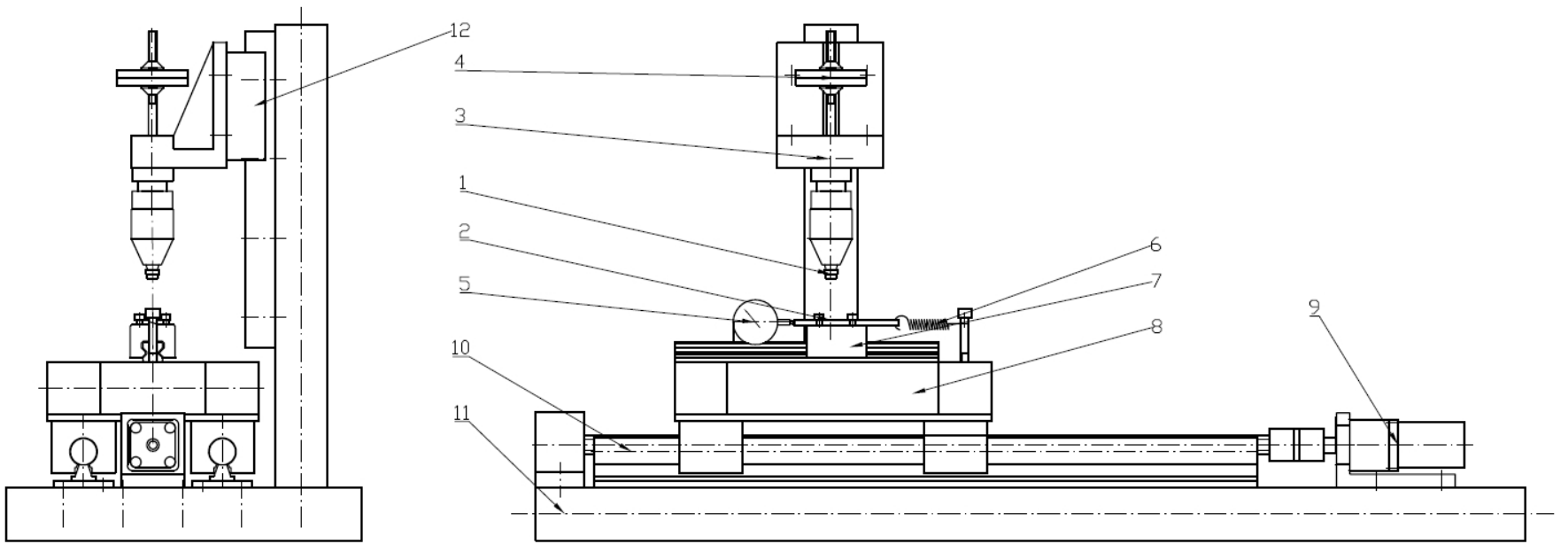

Figure 9. Test stand: 1 -specimen; 2 -counter-specimen (metal plate); 3-specimen clamping assembly; 4-weights; 5-force sensor; 6-stop spring; 7-upper carriage; 8-lower carriage; 9-stepper motor with gearbox; 10 -linear guide for the lower carriage; 11 -base; 12 -linear guide for specimen clamping.

The test stand consists of two assemblies. The function of the first assembly is to rigidly clamp one end of the specimen. The second assembly consists of two carriages that hold the other end of the specimen. The drive system is responsible for increasing the cutting force until the metal-polymer bond is broken. The drive assembly uses a bipolar, two-phase stepper motor. The usage of stepper motors allow for very accurate positioning of the rotating shaft position. Controlling the frequency of control impulses allows the rotational speed to be changed with simultaneous control of the executed displacement. By using this type of drive, it is possible to set a precise value of displacement and control the increase in shear force. 


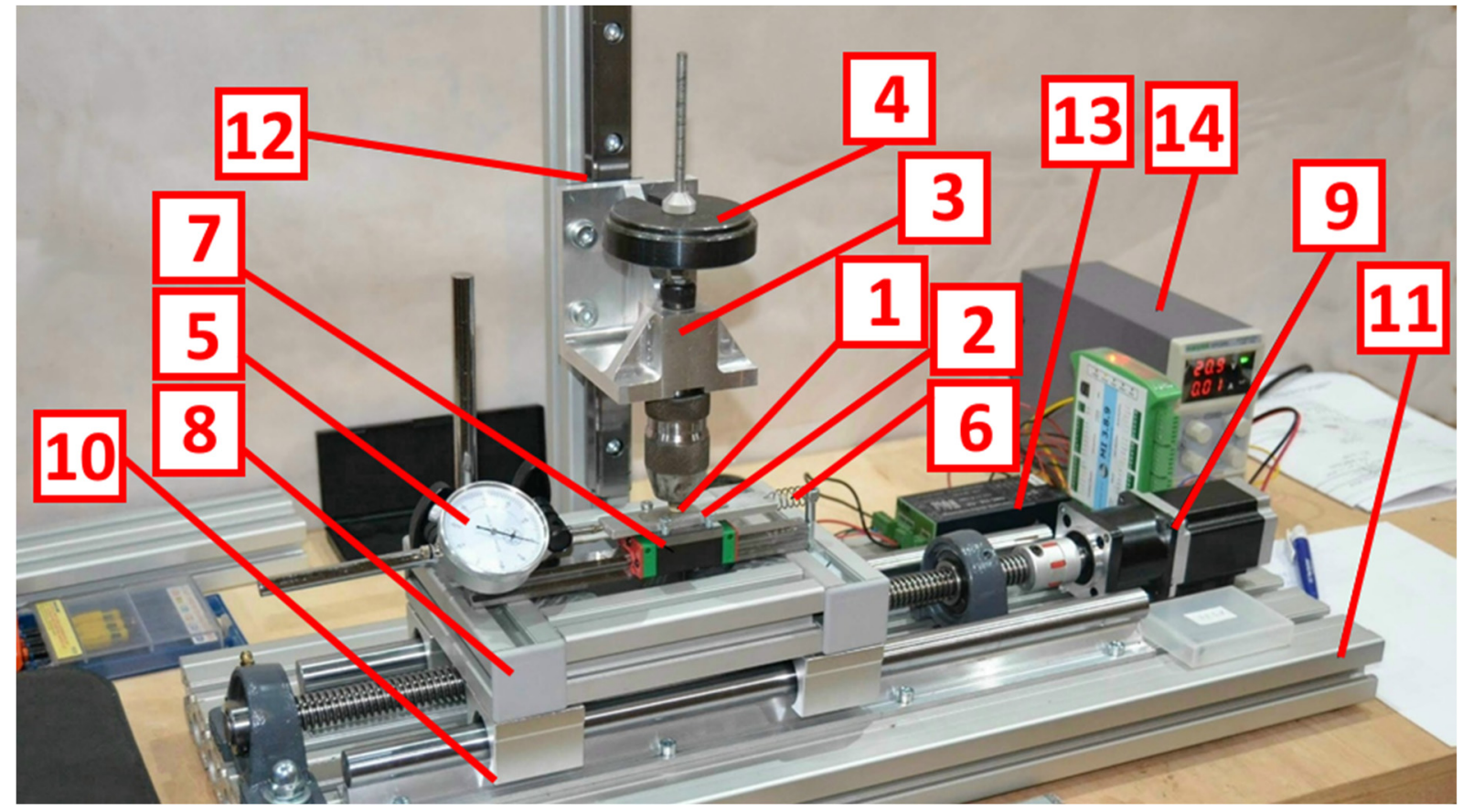

Figure 10. Test stand: 1-specimen; 2-counter-specimen (metal plate); 3-specimen clamping assembly; 4-weights; 5-force sensor; 6-stop spring; 7-upper carriage; 8-lower carriage; 9 stepper motor with gearbox; 10-linear guide for the lower carriage; 11-base; 12 -linear guide for specimen clamping; 13-stepper motor controller; 14-power supply unit.

The tests were carried out with 3 repetitions. During the tensile and shear tests, the maximum force was determined. An example of the recorded shear force values is shown in Figure 11.

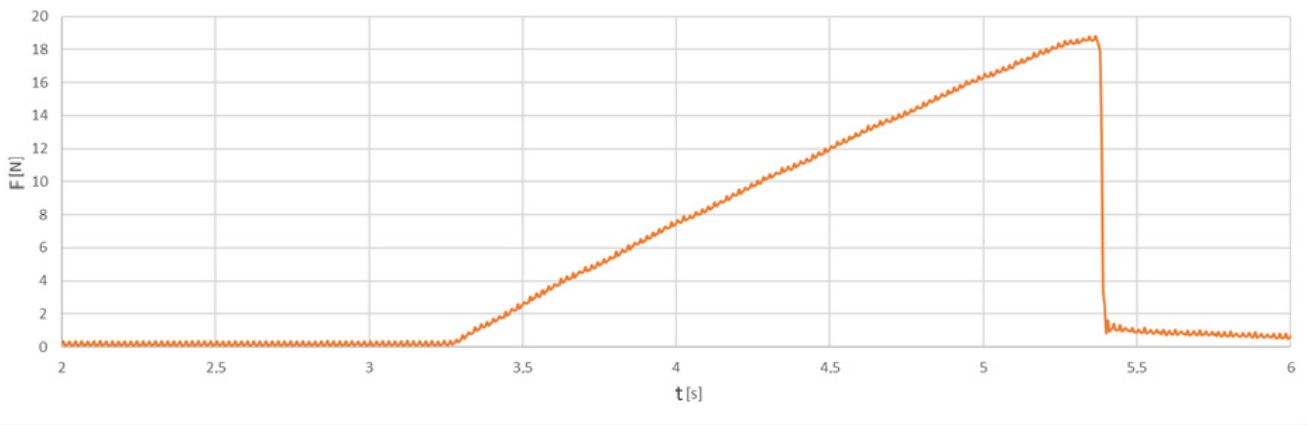

Figure 11. An example of the force trend during the metal-polymer shear strength test.

The maximum value of the force at which the rupture of the bond occurred is clearly visible in the presented chart. Using the maximum force values, the strength was calculated. The size of the nominal contact area was different for each of the tested samples. The differences resulted from the 3D FDM printing technology, which caused changes in the shape and size of the joint surface. When calculating the rupture stress, the size variation in the contact area was taken into account.

\subsubsection{Tribological Studies}

The gold standard in tribological research is the use of a pin-on-disc test stand. However, it is not possible to achieve reciprocating motion that mimics the way the materials cooperate in the prosthetic joint on a pin-on-disc stand. In order to ensure the samples had a standardized form, the ASTM G99-17 standard was used. This standard describes 
testing with the use of a pin-on-disc test stand, although the samples intended for the pin-on-disc test stand are well suited for the test stand used in the tests (described below). The plastic-coated sample had a cylindrical shape (cylinder diameter of $8 \mathrm{~mm}$ and height of $10 \mathrm{~mm})$.

During the tribological tests, a 3D-printed cylindrical specimen was pressed with a normal force onto a Ti6Al4V titanium alloy plate. The unit pressure in tribological tests was $p=1 \mathrm{MPa}$. Two types of tests were performed:

- Tests for the coefficient of static friction $\mu_{0}$,

- Tests for the coefficient of kinetic friction $\mu$.

Both types of tests were performed for dry friction and in the presence of water. The friction pair operated dry in the first stage of the test and then water was added to the friction node. The friction force $\mathrm{F}$ was recorded at a frequency of $200 \mathrm{~Hz}$. Friction tests were carried out during reciprocating motion. A scheme of the friction pair used during the tests is shown in Figure 12.

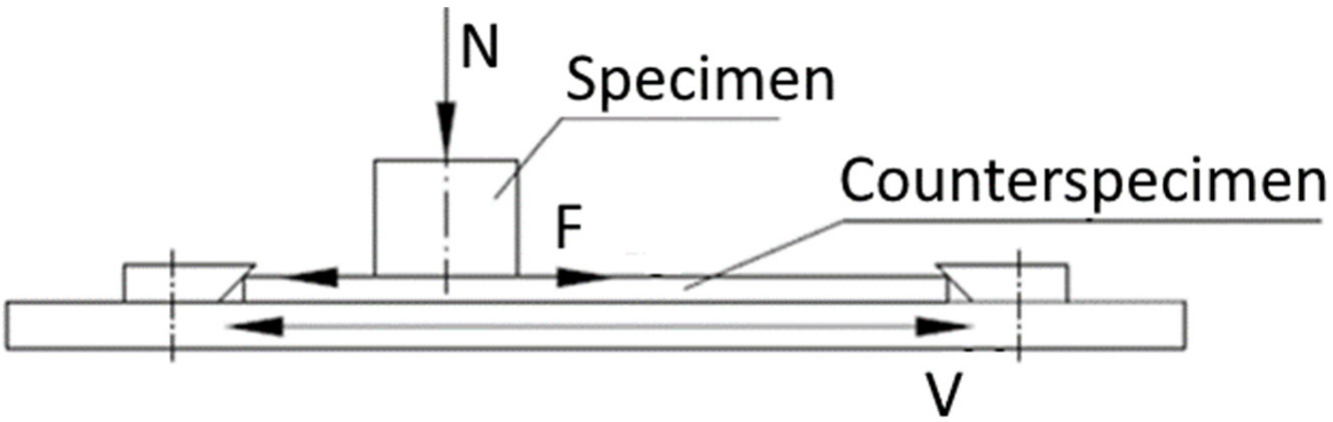

Figure 12. A kinematic scheme of the test stand used for testing friction during the reciprocating motion: $\mathrm{N}$-normal force; $\mathrm{F}$-friction force; $\mathrm{V}$ - velocity.

The tested friction pair consisted of materials that may occur in the implant with metal-polymer components. Three friction pair were tested:

- PLA-Ti6A14V;

- PA-Ti6Al4V;

- Ti6Al4V-Ti6Al4V.

During static friction coefficient testing, a titanium plate mounted on a moving carriage performed a motion cycle that consisted of 20 motions. During the motion cycle, the test stand performed slow movements $(\mathrm{V}=1 \mathrm{~mm} / \mathrm{s})$ in both directions. There was a break of $2 \mathrm{~s}$ between movements. The distance in each direction was different, which meant the starting point changed for each motion (Figure 13).

Elastomeric washers used between the force sensor and the carriage caused the value of the force to increase gradually during the movement. As soon as the friction force reached a value equal to the static friction force the motion occurred. The transition from static to kinetic friction resulted in an immediate decrease in the measured force. The peak value of the friction force was assumed as the static friction force (Figure 14).

After one measurement series, 40 static friction force values were obtained. The mean value from 36 measurements (the 4 most extreme values were rejected) was taken as the static friction force value. The average static friction force values were used to calculate static friction coefficients.

The kinetic friction coefficient tests were performed in reciprocating motion at a sliding velocity of $V=20 \mathrm{~mm} / \mathrm{s}$. The friction force was taken as the value after the velocity stabilized. 


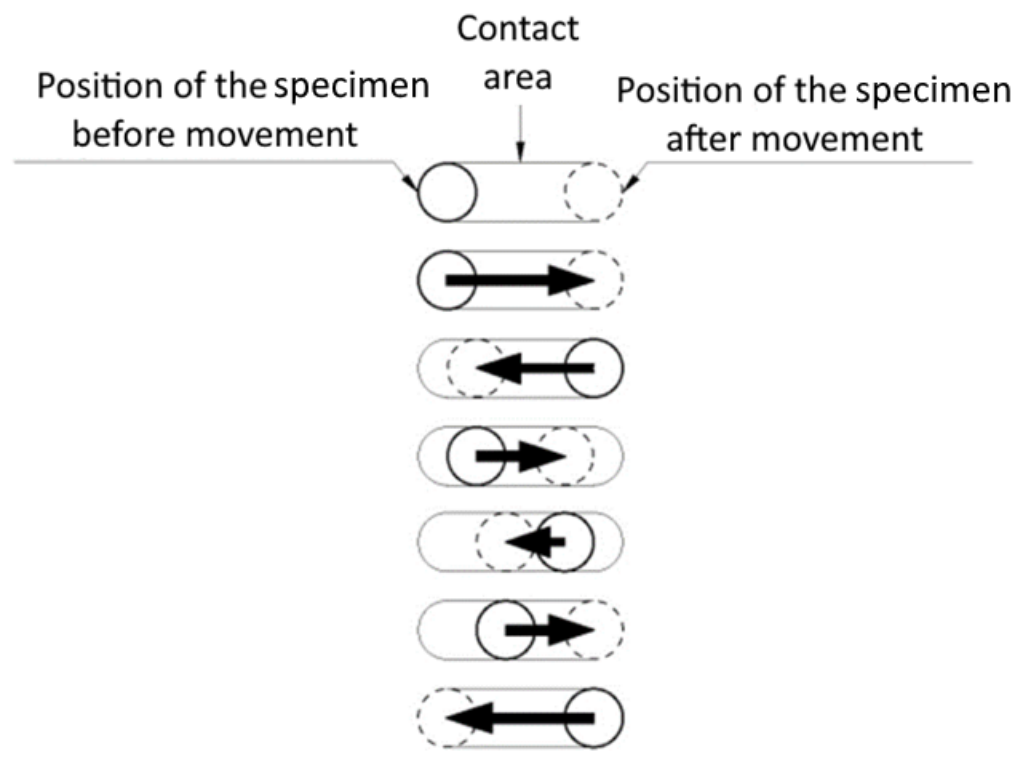

Figure 13. Specimen displacement during static friction measurements.

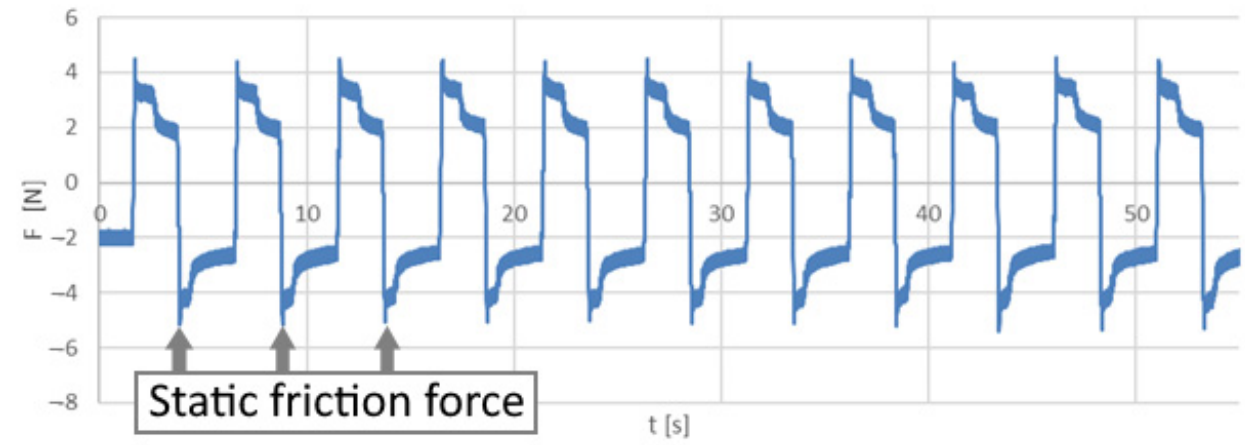

Figure 14. An example of the friction force values recorded during the static friction test.

\subsubsection{Microscopic Observations}

Titanium alloy-polymer bonds were subjected to microscopic observations. The bonds were checked before detachment and the surface of the polymer sample was observed after detachment. The tests were performed using a Nikon Eclipse MA200 light microscope. The observations were made at magnifications in the range of 100-500x. The images were recorded with a Visitron Systems digital camera with Spot Advanced and NIS Elements BR software. Metallographic specimens were prepared using a grinding and mechanical polishing process.

Microscopic observations were also carried out using a Phenom XL scanning electron microscope at magnifications of 500-2000x. An accelerating voltage range of 5-25 kV was applied during the experiments. Material contrast observations were performed using SE and BSE detectors.

\section{Results}

\subsection{Results of Strength Tests}

The tear and shear rupture stress values are summarized in Table 4.

As it can be observed, higher tensile strength (both at rupture and shear) was seen in components made of PLA. For PLA-Ti6Al4V bonds, the effect of surface roughness on tensile strength was observed. For samples with higher roughness, the tensile strength was almost doubled.

For PA-Ti6Al4V bonds, the rupture strength was very low. Many PA prints detached from Ti6Al4V during transit or after attaching to test equipment holders. 
Table 4. Rupture stress values of the tested Ti6Al4V-polymer bonds.

\begin{tabular}{cccc}
\hline \multirow{2}{*}{ Material } & Type of Load & \multicolumn{2}{c}{ Stress at Rupture of the Bond [MPa] } \\
\cline { 3 - 4 } & Tension & $\begin{array}{c}\text { Metal Specimen with } \\
\text { Lower Roughness }\end{array}$ & $\begin{array}{c}\text { Metal Specimen with } \\
\text { Higher Roughness }\end{array}$ \\
\hline \multirow{2}{*}{ PLA } & Shear & $1.84 \pm 0.50$ & $3.47 \pm 1.91$ \\
& Tension & $0.42 \pm 0.18$ & $1.00 \pm 0.14$ \\
\hline \multirow{2}{*}{ PA } & Shear & $0.43 \pm 0.18$ & $0.05 \pm 0.01$ \\
& & & $0.02 \pm 0.01$ \\
\hline
\end{tabular}

The average rupture stress values are presented in Figures 15 and 16.

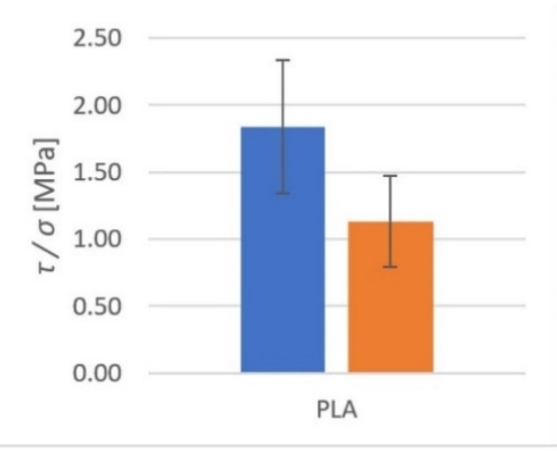

(a)

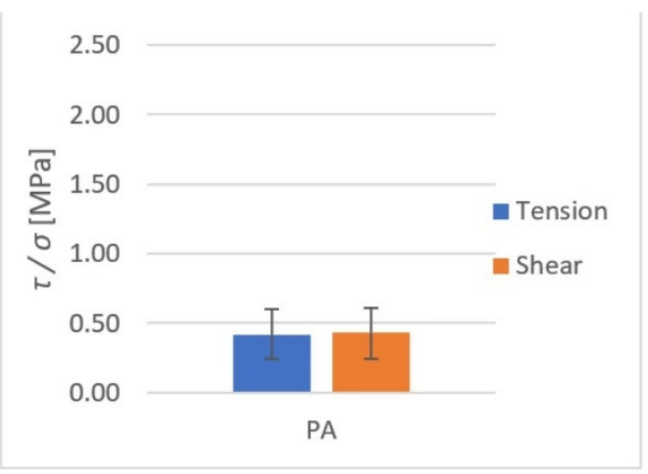

(b)

Figure 15. The shear and tensile strengths of the tested metal (Ti6Al4V)-polymer components: (a) PLA; (b) PA.

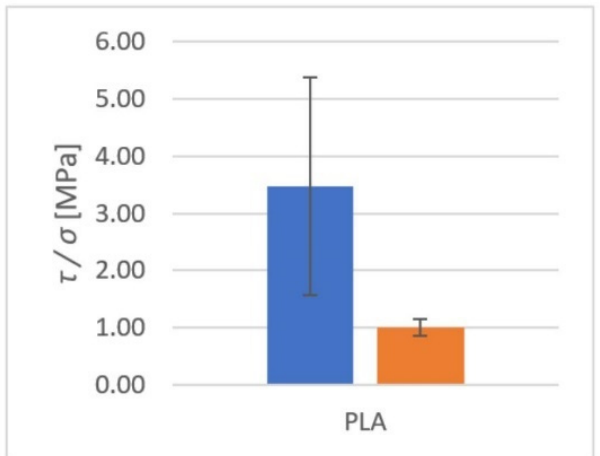

(a)

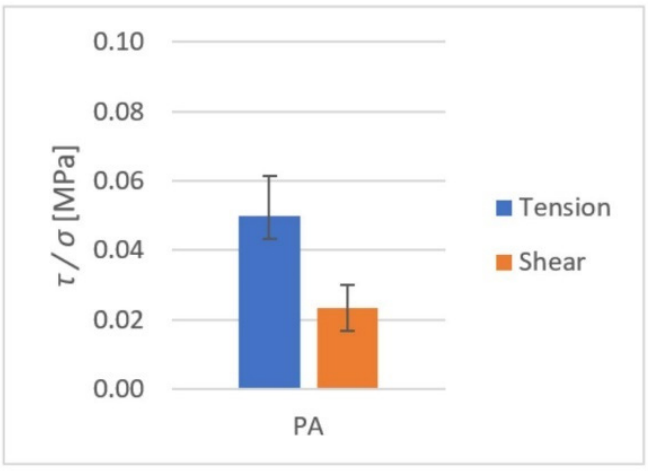

(b)

Figure 16. The shear and tensile strengths of the tested metal (Ti6Al4V)-polymer components: (a) PLA; (b) PA.

\subsection{Results of Microscopic Observations}

In order to formulate a qualitative assessment of the Ti6Al4V-polymer bonds, microscopic observations of the bonding area were carried out. In addition, the surfaces of polymer samples detached from Ti6Al4V were examined. Microscopic observations of the samples revealed differences in the quality of the metal-polymer bonds.

\subsubsection{Ti6Al4V-PLA Bond}

The images recorded during the analysis of the Ti6Al4V (lower roughness)-PLA bonds are presented in Figure 17. 


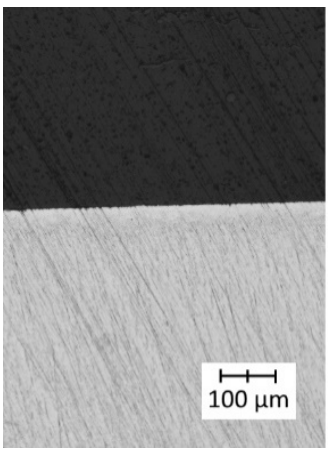

(a)

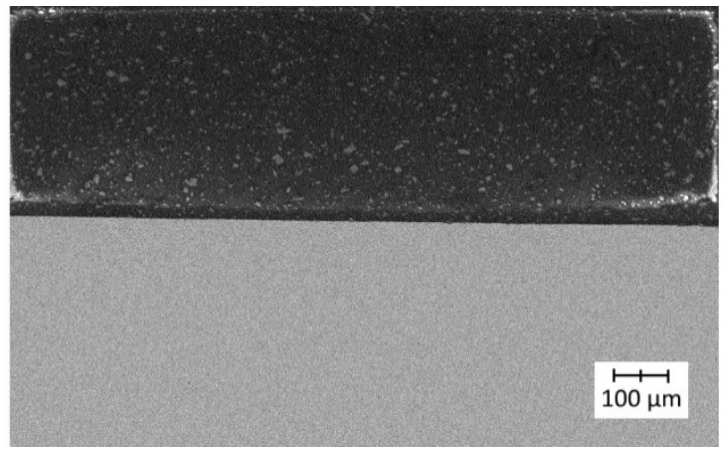

(b)

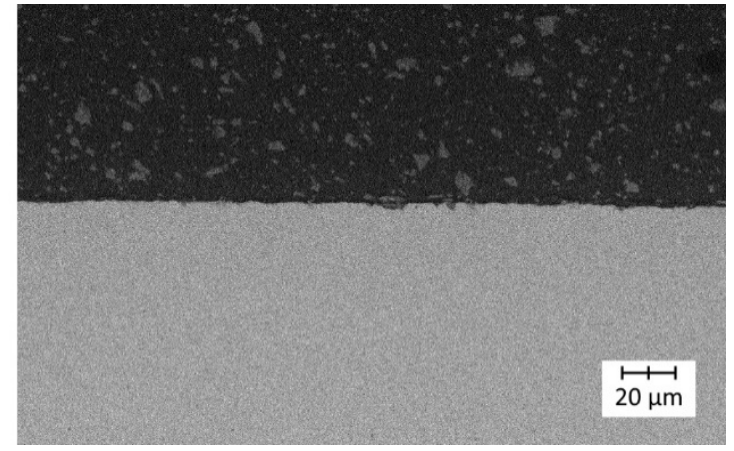

(c)

Figure 17. Microscopic images of Ti6Al4V (lower roughness)-PLA bonds: (a) light microscopy-a continuous metal-polymer bond was visible; (b) SEM (lower magnification)—a high-quality metalpolymer bond was visible; (c) SEM (higher magnification)—a high-quality metal-polymer bond was visible.

The images recorded during the analysis of the Ti6Al4V (lower roughness)-PLA bonds are presented in Figure 18.

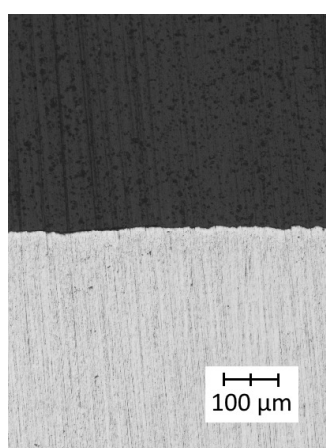

(a)

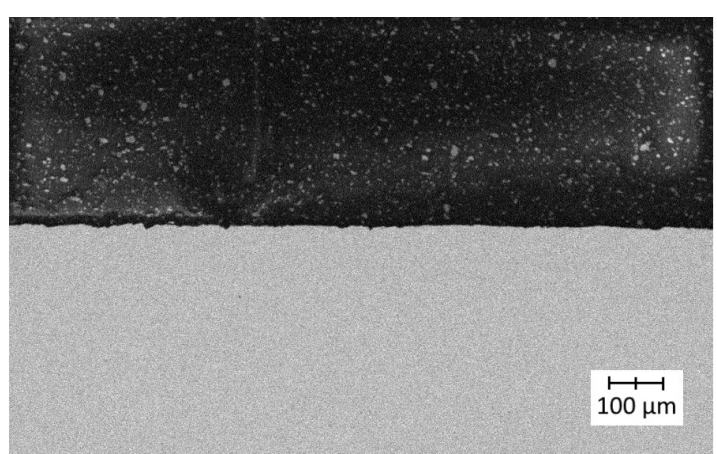

(b)

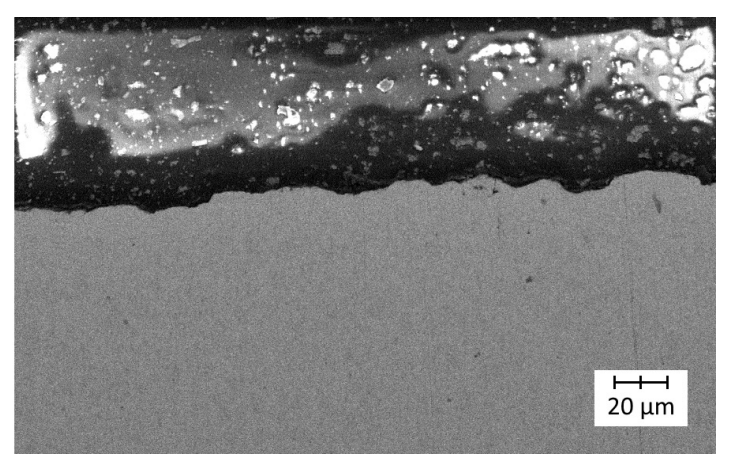

(c)

Figure 18. Microscopic images of Ti6Al4V (higher roughness)-PLA bonds: (a) light microscopy-a continuous metal-polymer bond was visible; (b) SEM (lower magnification) - a high-quality metalpolymer bond was visible; (c) SEM (higher magnification)—a high-quality metal-polymer bond was visible.

The microscopic observations of Ti6Al4V-PLA bonds revealed that in both cases (for lower and higher roughness levels of the titanium alloy specimen) the interface was continuous and free from delamination, pores, blisters, or other structural defects. The different surface roughness levels of the metal substrate did not affect the quality of the bonds.

The images recorded for PLA detached from a Ti6Al4V titanium alloy sample with lower roughness are presented in Figure 19. Images recorded for PLA detached from a Ti6Al4V titanium alloy sample with higher roughness are presented in Figure 20.

After detaching the PLA sample, the surface texture seemed to be smoother than for PA. This indicated that the actual adhesion surface was greater for PLA than for PA, which could be responsible for the higher strength of Ti6Al4V-PLA bonds compared to Ti6Al4V-PA bonds. 


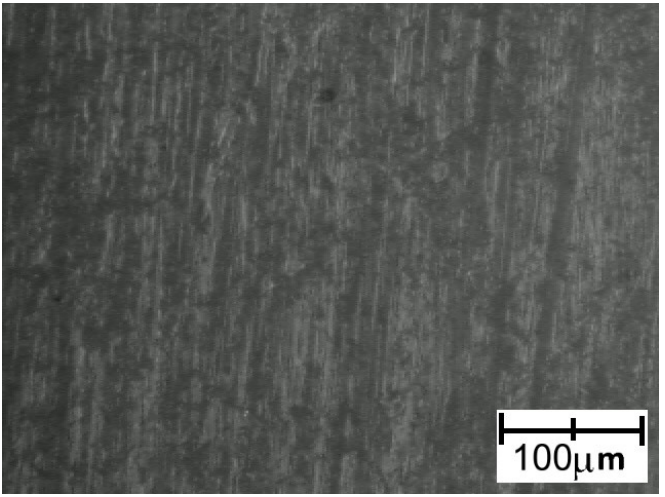

(a)

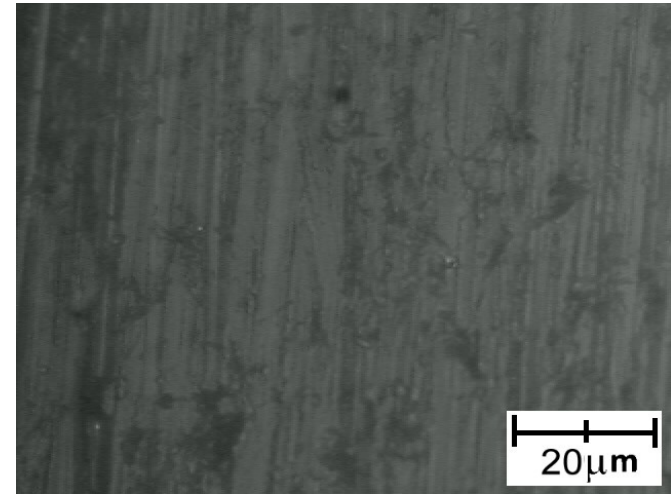

(b)

Figure 19. Microscopic images of the PLA surface after detaching from Ti6Al4V titanium alloy with lower roughness: (a) low magnification; (b) high magnification.

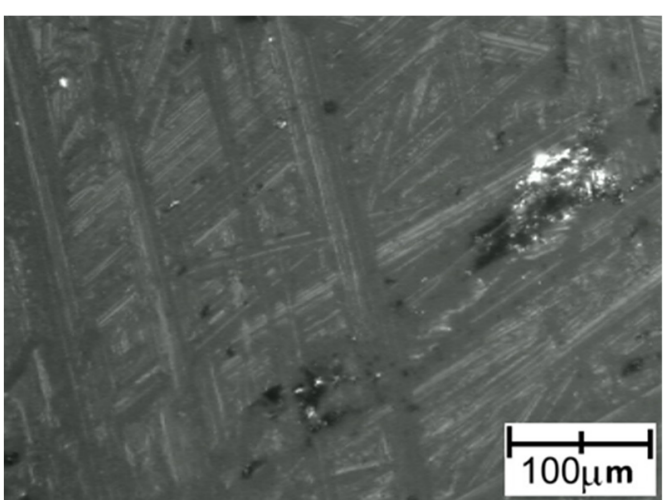

(a)

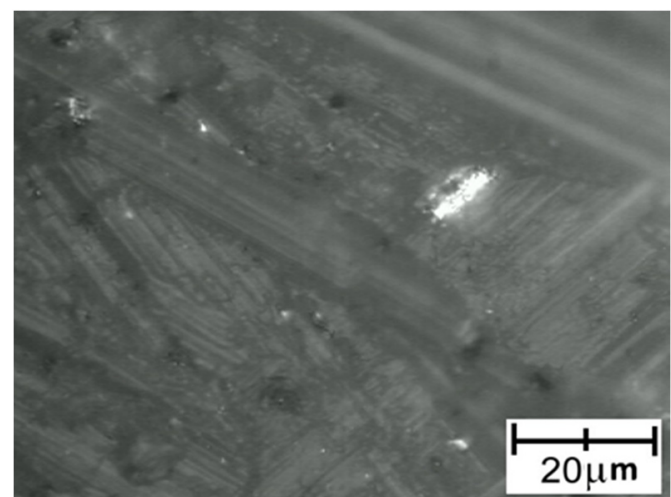

(b)

Figure 20. Microscopic images of the PLA surface after detaching from Ti6Al4V titanium alloy with higher roughness: (a) low magnification; (b) high magnification.

\subsubsection{Ti6Al4V-PA Bond}

The images recorded during the analysis of the Ti6Al4V (lower roughness)-PA bonds are presented in Figure 21. The Ti6Al4V (higher roughness)-PA bonds were so highly unstable that complete discontinuity of the bonds occurred, meaning this specimen could not be microscopically examined.

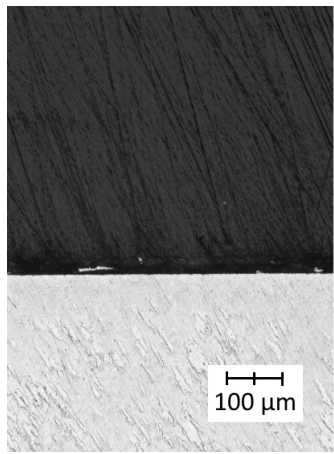

(a)

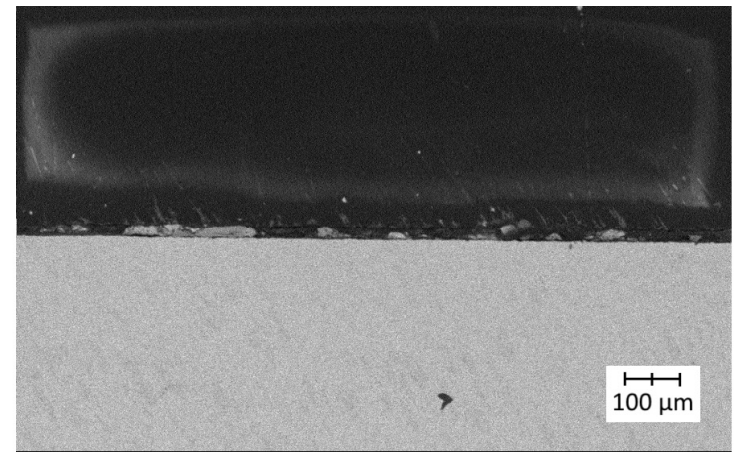

(b)

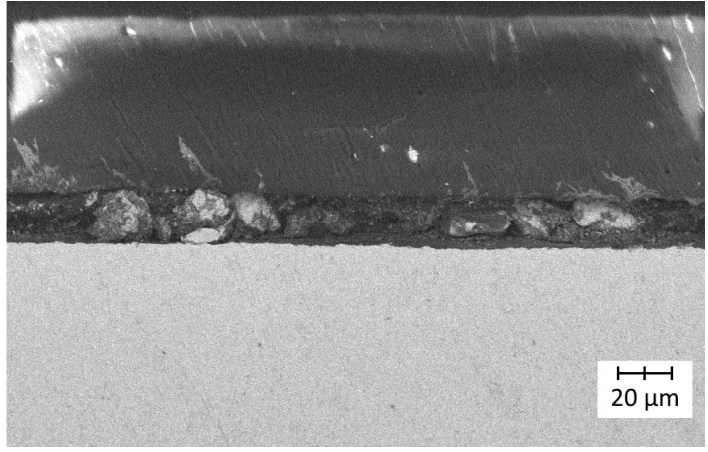

(c)

Figure 21. Microscopic images of Ti6Al4V (lower roughness)—PA bonds: (a) light microscopy—a continuous metal-polymer bond was visible; (b) SEM (lower magnification)—a high-quality metalpolymer bond was visible; (c) SEM (higher magnification)—a high-quality metal-polymer bond was visible. 
In the terms of Ti6Al4V-PA bond, a lack of permanent connection between the polymer and the titanium substrate was observed. Local delamination between the materials was clearly visible.

Images recorded for PA detached from a Ti6Al4V titanium alloy with lower roughness are presented in Figure 22. Images recorded for PA detached from a Ti6Al4V titanium alloy with higher roughness are presented in Figure 23.

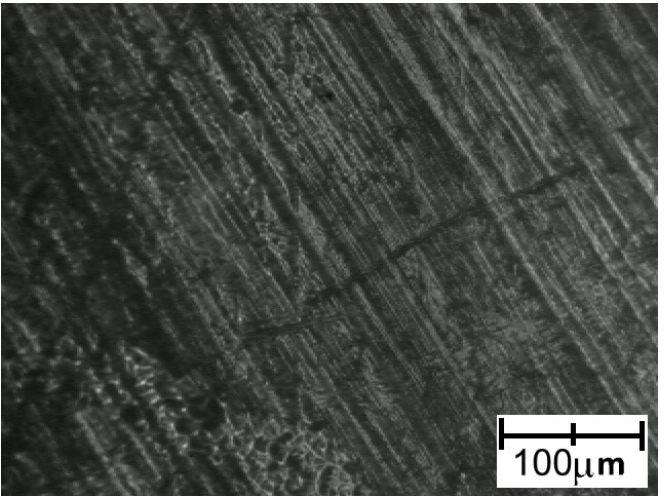

(a)

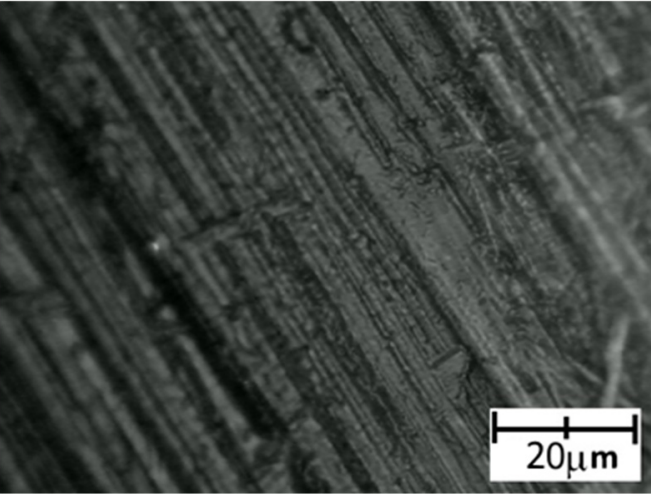

(b)

Figure 22. Microscopic images of PA surface after being detached from Ti6Al4V titanium alloy with lower roughness: (a) low magnification; (b) high magnification.

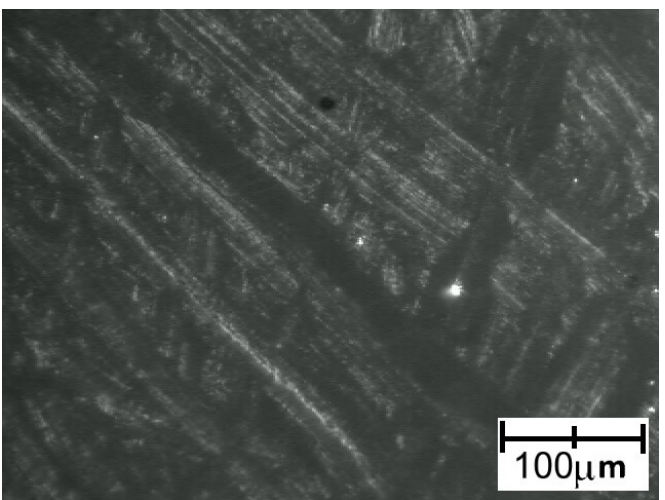

(a)

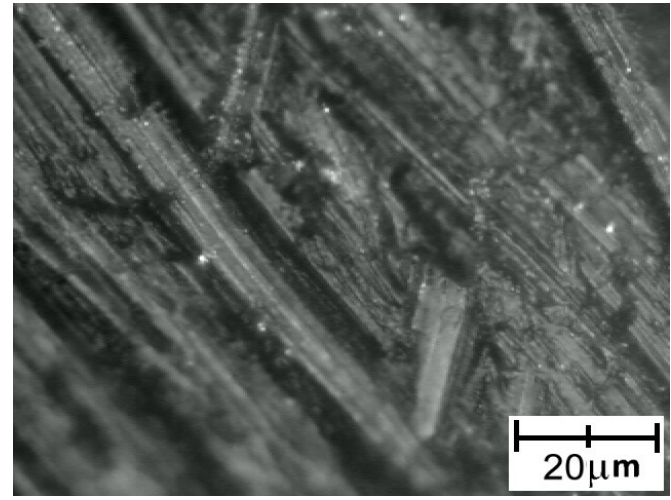

(b)

Figure 23. Microscopic images of PA surface after being detached from Ti6Al4V titanium alloy with higher roughness: (a) low magnification; (b) high magnification.

Although the surface of the metal component showed increased roughness, the polymer surface texture seemed to be smooth.

\subsection{Result of Tribological Tests}

The results of tribological tests are shown in Table 5.

Table 5. Static and kinetic friction coefficients.

\begin{tabular}{ccccc}
\hline \multirow{2}{*}{ Tribological Pair } & \multicolumn{2}{c}{ Dry Friction } & \multicolumn{2}{c}{ Friction in the Presence of Water } \\
\cline { 2 - 5 } & $\boldsymbol{\mu}$ & $\boldsymbol{\mu}_{\mathbf{0}}$ & $\boldsymbol{\mu}$ & $\boldsymbol{\mu}_{\mathbf{0}}$ \\
\hline PLA-Ti6Al4V & 0.59 & 0.62 & 0.36 & 0.52 \\
PA-Ti6A14V & 0.18 & 0.19 & 0.15 & 0.15 \\
Ti6Al4V-Ti6Al4V & 0.39 & 0.44 & 0.33 & 0.54 \\
\hline
\end{tabular}

The results of the tribological tests are also presented in the form of graphs (moving average) in Figures 24-26. 


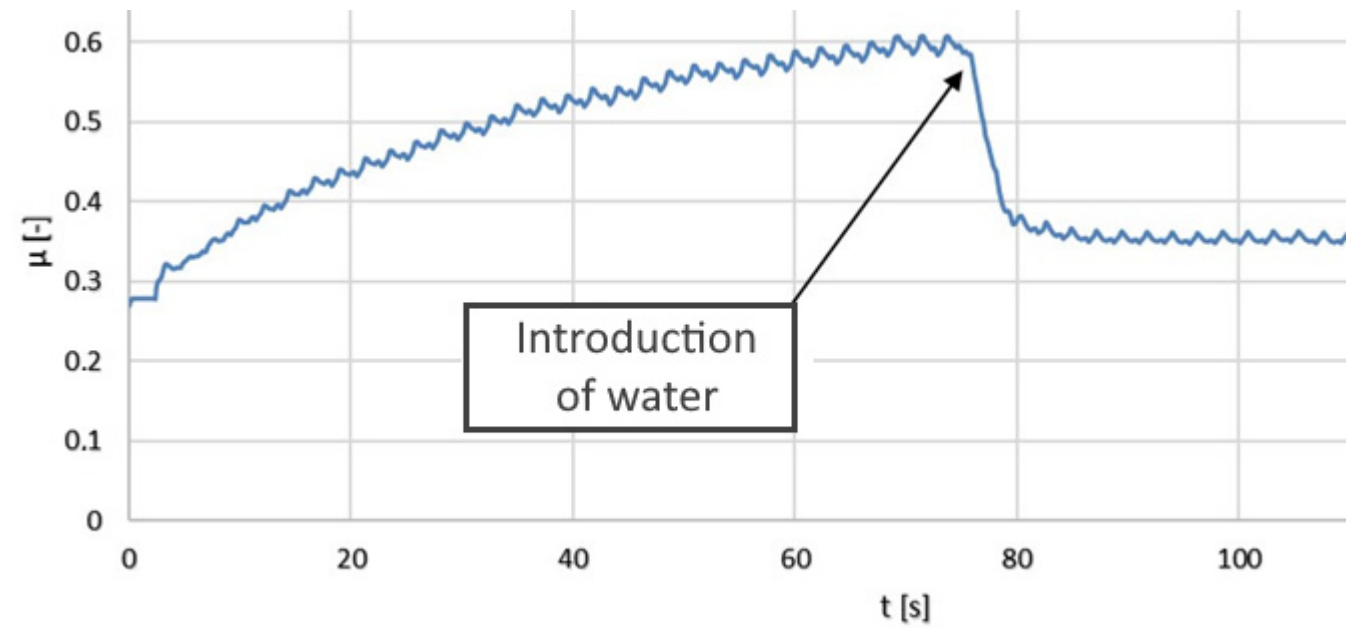

Figure 24. The kinetic friction coefficient $\mu$ values for the pair composed of Ti6Al4V and PLA, showing dry friction and friction in the presence of water.

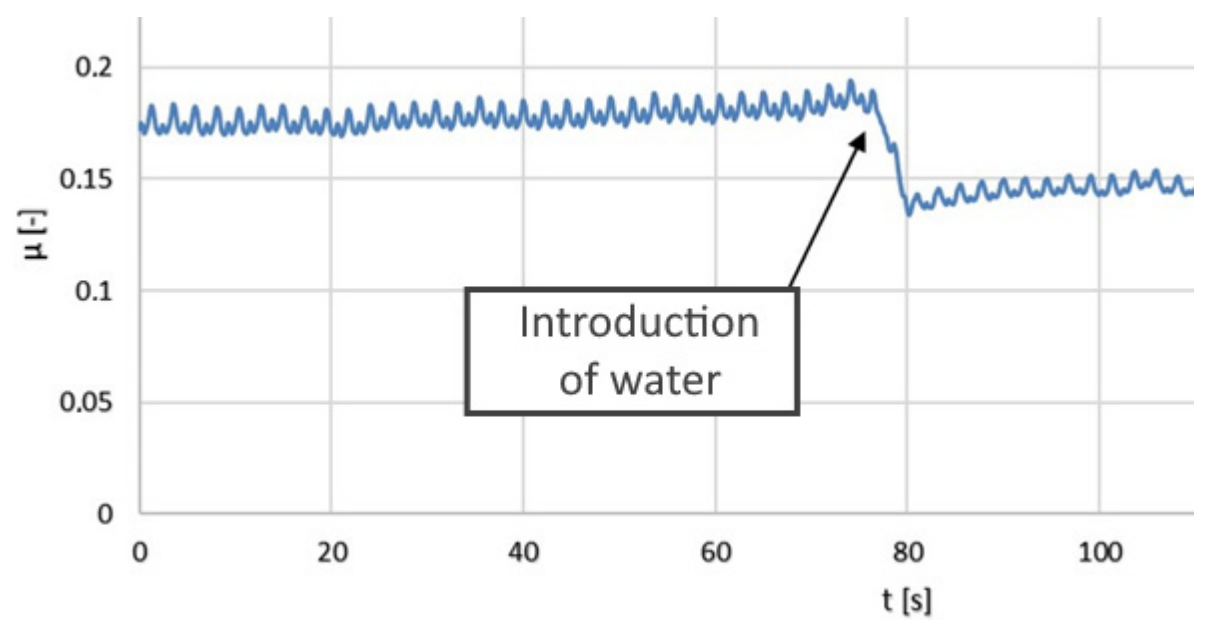

Figure 25. The kinetic friction coefficient $\mu$ values for the pair composed of Ti6Al4V and PA, showing dry friction and friction in the presence of water.

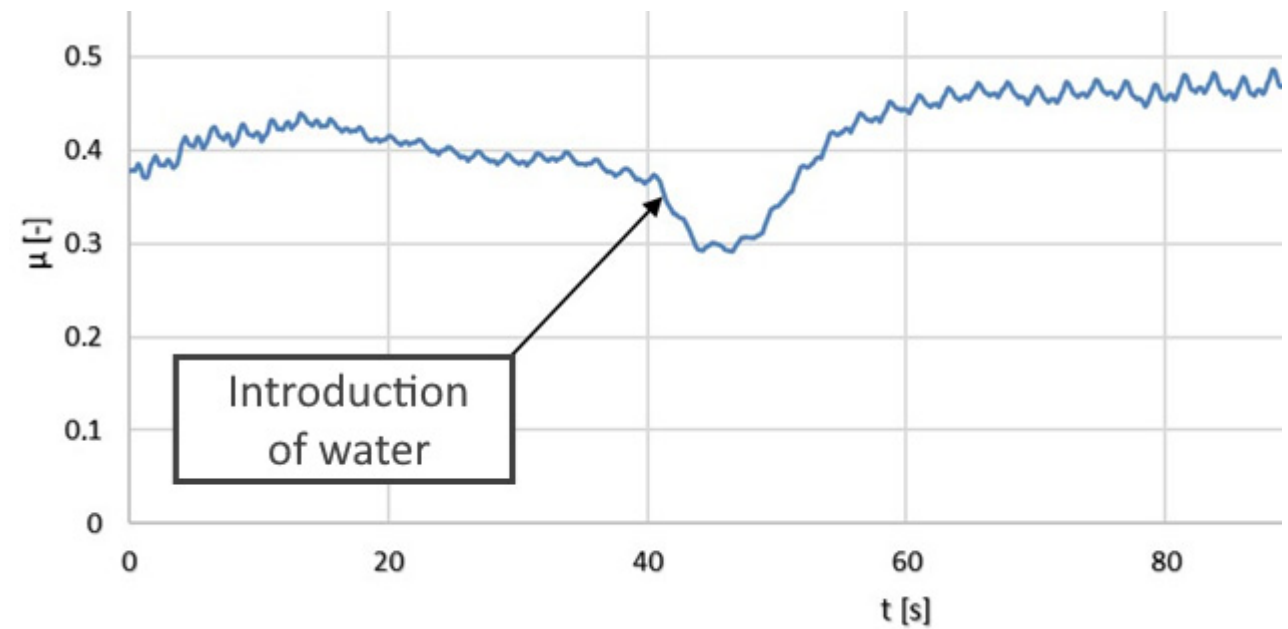

Figure 26. The kinetic friction coefficient $\mu$ values for the pair composed of Ti6Al4V and Ti6Al4V, showing dry friction and friction in the presence of water. 
The friction coefficient values for the PLA-Ti6Al4V pair increased with time. A slight seizing effect occurred. When water was applied, the coefficient of friction decreased significantly. Dry operation should not be allowed for this type of friction pair.

In the terms of the PA-Ti6Al4V pair, the friction coefficient values were significantly lower than for the PLA-Ti6Al4V pair. Water had a positive effect on the coefficient of friction. Seizing did not occur for the analyzed friction pair. The friction coefficient was stable and relatively low, which confirmed the good tribological properties of PA.

For the MoM (metal-on-metal) Ti6Al4V-Ti6Al4V pair, the presence of water had a very brief effect. A continuous increase in the resistance to motion was observed. This is typical for pairs consisting of two parts made of the same material. The oxide layer was destroyed, strong adhesive interactions occurred and seizing emerged. The measured kinetic friction coefficient values for this pair were higher than for the Ti6Al4V-PA pair but lower than for the Ti6Al4V-PLA pair.

All results from both the kinetic and the static friction tests are presented in Figures 27-29.

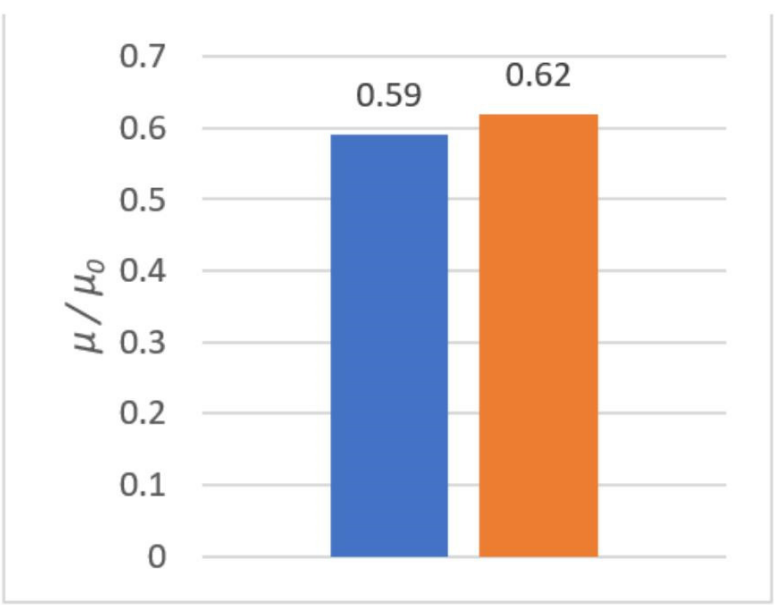

(a)

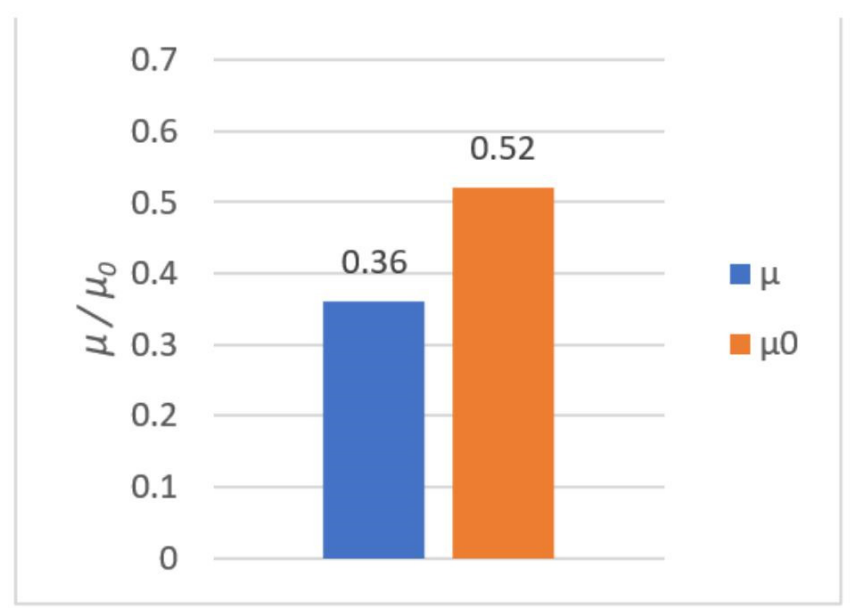

(b)

Figure 27. The results of tribological investigations of the PLA-Ti6Al4V pair: (a) dry friction; (b) friction in the presence of water.

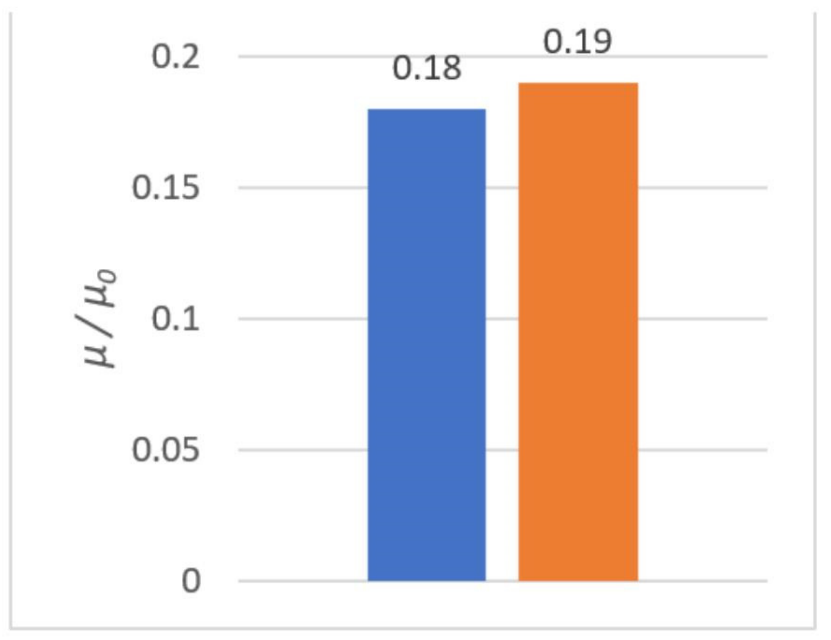

(a)

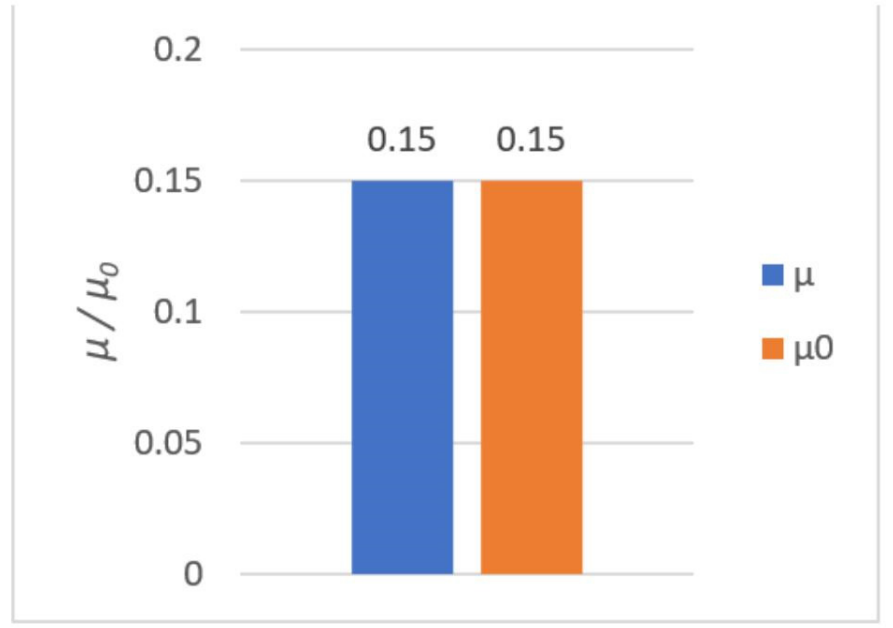

(b)

Figure 28. The results of tribological investigations of the PA-Ti6Al4V pair: (a) dry friction; (b) friction in the presence of water. 


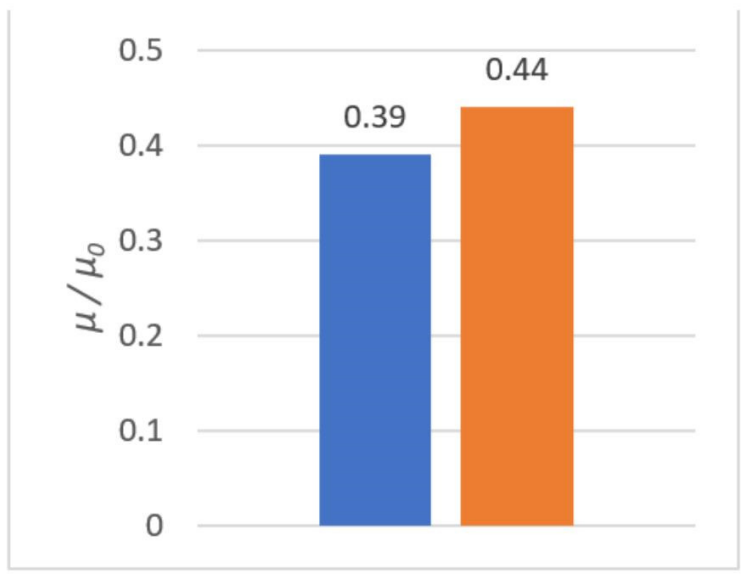

(a)

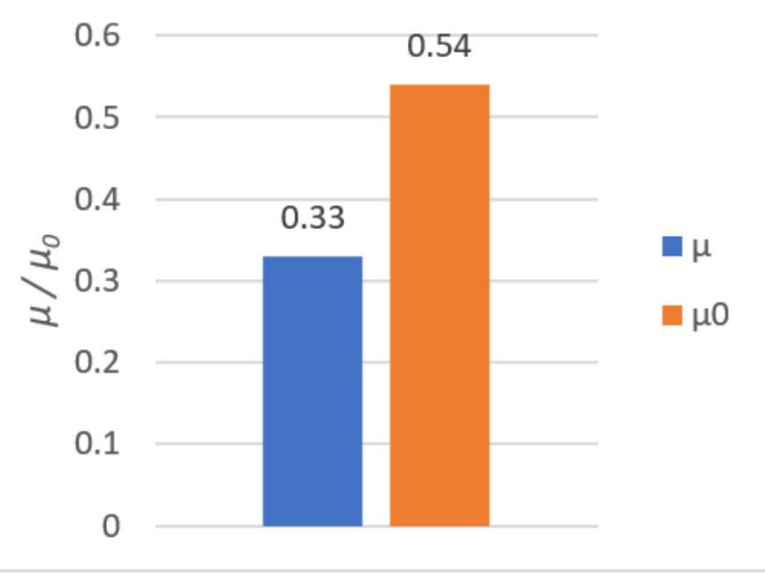

(b)

Figure 29. The results of tribological investigations of the Ti6Al4V-Ti6Al4V pair: (a) dry friction; (b) friction in the presence of water.

\section{Discussion}

\subsection{Strenght Tests}

Analyzing the results of the tensile and shear strength tests of metal-polymer bonds, it can be concluded that:

- The deposition of the biocompatible material by 3D FDM printing on titanium alloy was possible; however, the rupture strength of the tested bonds was low. The prints made from PLA had a tensile strength range of about 20 to $80 \mathrm{MPa}$ [74,75]. This range was very wide, since the mechanical properties of FDM 3D-printed element depend on numerous printing parameters. The sample printed with the same parameters as in this article had a strength value of $29 \mathrm{MPa}$. In terms of the 3D FDM-printed $\mathrm{PA}$, the strength was approximately $33 \mathrm{MPa}[76,77]$. The obtained strength values for metal-polymer bonds did not exceed 2 MPa at tension and 3.5 MPa at shear. The rupture strength of the metal-plastic bond was much lower than the rupture strength of the weaker polymer material;

- The results of the strength tests showed expanded uncertainty (expanded uncertainty is up to $55 \%$ of the mean value). This means that the process of printing had low repeatability and the bonds were characterized by different rupture strengths;

- The usage of FDM 3D printing to deposit plastic as a part of the manufacturing process of endoprostheses would require an improvement, since the tensile and shear strength were too low and the repeatability of the printing process was poor;

- Ti6Al4V-PA bonds had 2-4 times lower tensile and shear strengths than Ti6Al4V-PLA;

- The effect of surface roughness on tensile strength was observed only for Ti6Al4V-PLA components. For samples with higher roughness, the tensile strength of the bonds was almost doubled. For shear strength, the effect of roughness was negligible.

The surface free energy value for PLA [78] is similar to that of PA [79], so adhesive interactions with titanium alloy will have similar strengths for both plastics. The parameter that differs between the investigated plastics is the thermal expansion coefficient. This is crucial, since the print shrinks and microslides between plastic and metallic substrates occur during cooling. As a result, the adhesive and mechanical bonds are broken. PLA has a significantly lower thermal expansion coefficient than PA [80,81]. Moreover, PLA needs to be heated to a lower temperature than PA to achieve material flow. As a result, the temperature difference during cooling is smaller for PLA and the shrinkage is also smaller. Therefore, the difference between the shrinkage of Ti6Al4V and PLA is smaller than that of Ti6Al4V and PA. Hence, in terms of Ti6Al4V-PLA, fewer adhesive and mechanical bonds 
are destroyed. This is another potential explanation for why Ti6Al4V-PA bonds have significantly lower tensile and shear strengths than Ti6Al4V-PLA bonds.

The higher strength of Ti6Al4V-PLA may also be a result of a larger actual contact area. PLA likely has the ability to fill surface irregularities better. Here, PA did not fill the irregularities as well, and as a result the strength of the mechanical bonds was lower and adhesive bonds were formed only on the tops of irregularities. During the tests of PA-Ti6Al4V components, no effect of surface roughness on the bond strength was observed, which may also confirm that at higher roughness levels the irregularities are not filled and the effect of increased roughness is not visible. The melt mass-flow rate (MFR) for PLA was $14.48 \mathrm{~g} / 10 \mathrm{~min}\left(\mathrm{load}=2.16 \mathrm{~kg}\right.$, temperature $\left.=190^{\circ} \mathrm{C}\right)[65]$ and for PA was $9.23 \mathrm{~g} / 10 \mathrm{~min}$ (load $=5.00 \mathrm{~kg}$, temperature $=235^{\circ} \mathrm{C}$ ) [66]. This means that PLA is more fluid and easier to process by extrusion. The greater fluidity of the material probably caused the better filling of irregularities.

Additionally. 3D FDM prints differ significantly from elements made using the conventional injection method due to their layered structure [82]. The destruction of a 3D FDM print starts with damage between the layers [69]. The weak points of 3D prints are the defects between the layers, namely the voids, air gaps and points of stress concentration [83-85]. Microscopic observations of the PA-Ti6Al4V bonds showed that local delamination between the materials was clearly visible. It is very possible that the abovementioned defects also appear at the metal-plastic interface and reduce the strength of the bond. When improving the method used for depositing plastics onto metals, special attention ought to be paid to preventing such defects.

\subsection{Tribological Tests}

The tribological tests allowed us to evaluate the sliding properties of materials intended for 3D printing of metal-polymer components for implants. After analyzing the obtained values of coefficient of friction, it was concluded that:

- The friction pair Ti6Al4V-PA had the lowest coefficient of friction. The coefficient of friction values were low at 0.15 in terms of dry friction and 0.18 in presence of water. Seizure was not observed during the use of these materials. One of the most frequently used pairs in endoprostheses is an UHMWPE cup with a Ti6Al4V head. For such pairs, the coefficient of friction (dry friction) is in the range of 0.07-0.14 [86]. Hence, the coefficient of friction value of 0.15 for Ti6Al4V-PA was very good;

- The PLA-Ti6Al4V pair showed a significant coefficient of friction value of $\mu=0.59$. Therefore, PLA is not suitable for cooperation with titanium alloy in endoprostheses. PLA could be used as a material for scaffolds printed directly onto titanium alloy. Such scaffolds could be introduced in selected regions of the endoprosthesis to support tissue growth. Moreover, due to the biodegradability of PLA, the scaffold could be later removed from the patient's body. The FDM method is well suited for creating scaffolds [87];

- The presence of water lowered the coefficient of friction values for most of the tested friction pairs. The Ti6Al4V-Ti6Al4V pair was an exception, since the coefficient of static friction in the presence of water was highest $(\mu 0=0.54)$;

- Ti6Al4V-PLA and Ti6Al4V-Ti6Al4V pairs had a tendency to seize. The addition of water reduced the coefficient of friction, although this effect was short-lived.

The authors of [35] proved that specimens 3D-printed from PCU had high porosity and absorbed lubricants better. Therefore, they acted similarly to the natural lubrication mechanism of the meniscus. In terms of the cooperation of PLA with Ti6Al4V, this kind of effect was not observed. The addition of a lubricant (water) caused that pair to seize. In terms of the Ti6Al4V-PA pair, the friction coefficient decreased by about $17 \%$ after the addition of water, and this effect persisted over time. Moreover, porosity in 3D FDMprinted PA specimens [88] is significantly lower than in PLA specimens [89]. The effect associated with porosity is probably not only caused by material processing by 3D FDM printing, but also likely depends on the material used. The porosity of the 3D FDM prints 
can be reduced or increased, e.g., by using other printing parameters [90]. While carrying out further work on the influence of pores on the tribological properties of 3D prints, it is worth testing samples from the same material but with different porosity levels.

\section{Conclusions}

This research showed that the deposition of PLA and PA by FDM 3D printing directly on Ti6Al4V titanium alloy is possible. However, the usage of FDM 3D printing to deposit plastic as a part of the manufacturing process of endoprostheses would require improvements, since the tensile and shear strength are too low and the repeatability of the printing process is poor. The benefits of the application of this method are so impressive that it is worth continuing work on this issue. Further research ought to be focused on improving the method of plastic deposition and attempts to use other materials.

Author Contributions: Conceptualization, D.G. and P.K.; methodology, M.K. and. P.K.; formal analysis, D.G., M.K. and P.K.; investigation, D.G., M.K. and P.K.; resources, M.K. and P.K.; writingoriginal draft preparation, D.G., M.K. and P.K.; writing-review and editing, M.K.; visualization, D.G., M.K. and P.K.; supervision, D.G.; project administration, D.G.; funding acquisition, D.G. All authors have read and agreed to the published version of the manuscript.

Funding: This research received no external funding.

Data Availability Statement: The data presented in this study are available on request from the corresponding author.

Conflicts of Interest: The authors declare no conflict of interest.

\section{References}

1. Kirschner, P. Hüftendoprothetik. Der Chirurg. 2005, 76, 95-104. [CrossRef]

2. Jamari, J.; Ammarullah, M.I.; Saad, A.P.M.; Syahrom, A.; Uddin, M.; van der Heide, E.; Basri, H. The Effect of Bottom Profile Dimples on the Femoral Head on Wear in Metal-on-Metal Total Hip Arthroplasty. J. Funct. Biomater. 2021, 12, 38. [CrossRef]

3. Allen, Q.; Raeymaekers, B. Surface Texturing of Prosthetic Hip Implant Bearing Surfaces: A Review. J. Tribol. 2021, 143, 040801. [CrossRef]

4. Qiblawey, Y.; Chowdhury, M.E.H.; Musharavati, F.; Zalnezhad, E.; Khandakar, A.; Islam, M.T. Instrumented Hip Implant: A Review. IEEE Sens. J. 2021, 21, 7179-7194. [CrossRef]

5. Drescher, P.; Oldorf, P.; Dreier, T.; Peters, R.; Seitz, H. Modification of joint prosthesis surfaces by ultrashort pulse laser treatment for improved joint lubrication. Curr. Dir. Biomed. Eng. 2019, 5, 57-60. [CrossRef]

6. Arkhipov, S.V.; Skvortsov, D.V. Ligamentum Teres and its Analog in the Hip Endoprosthesis-Necessary or Superfluous? A Systematic Review. Muscle Ligaments Tendons J. 2021, 11, 301. [CrossRef]

7. Sonntag, R.; Reinders, J.; Kretzer, J.P. Bio-Tribological Demands. In Materials for Total Joint Arthroplasty; Imperial College Press: London, UK, 2015; pp. 1-13.

8. Jamróz, W.; Szafraniec, J.; Kurek, M.; Jachowicz, R. 3D printing in pharmaceutical and medical applications. Pharm. Res. 2018, 35, 176. [CrossRef] [PubMed]

9. Javaid, M.; Haleem, A. Additive manufacturing applications in medical cases: A literature based review. Alex. J. Med. 2018, 54, 411-422. [CrossRef]

10. Tack, P.; Victor, J.; Gemmel, P.; Annemans, L. 3D-printing techniques in a medical setting: A systematic literature review. Biomed. Eng. Online 2016, 15, 1-21. [CrossRef]

11. Parthasarathy, J. 3D modeling, custom implants and its future perspectives in craniofacial surgery. Ann. Maxillofac. Surg. 2014, 4, 9-18. [CrossRef]

12. Fan, H.; Fu, J.; Li, X.; Pei, Y.; Li, X.; Pei, G.; Guo, Z. Implantation of customized 3-D printed titanium prosthesis in limb salvage surgery: A case series and review of the literature. World J. Surg. Oncol. 2015, 13, 1-10. [CrossRef]

13. Bagaria, V.; Bhansali, R.; Pawar, P. 3D printing-creating a blueprint for the future of orthopedics: Current concept review and the road ahead! J. Clin. Orthop. Trauma 2018, 9, 207-212. [CrossRef]

14. Ji, T.; Guo, W. The evolution of pelvic endoprosthetic reconstruction after tumor resection. Ann. Jt. 2019, 4, 29. [CrossRef]

15. Arabnejad, S.; Johnston, B.; Tanzer, M.; Pasini, D. Fully porous 3D printed titanium femoral stem to reduce stress-shielding following total hip arthroplasty. J. Orthop. Res. 2017, 35, 1774-1783. [CrossRef]

16. Kuznetsov, V.E.; Tavitov, A.G.; Urzhumtsev, O.D.; Mikhalin, M.V.; Moiseev, A.I. Hardware Factors Influencing Strength of Parts Obtained by Fused Filament Fabrication. Polymers 2019, 11, 1870. [CrossRef]

17. Syrlybayev, D.; Zharylkassyn, B.; Seisekulova, A.; Akhmetov, M.; Perveen, A.; Talamona, D. Optimisation of Strength Properties of FDM Printed Parts-A Critical Review. Polymers 2021, 13, 1587. [CrossRef] 
18. Martín, M.J.; Auñón, J.A.; Martín, F. Influence of Infill Pattern on Mechanical Behavior of Polymeric and Composites Specimens Manufactured Using Fused Filament Fabrication Technology. Polymers 2021, 13, 2934. [CrossRef] [PubMed]

19. Bonada, J.; Pastor, M.M.; Buj-Corral, I. Influence of Infill Pattern on the Elastic Mechanical Properties of Fused Filament Fabrication (FFF) Parts through Experimental Tests and Numerical Analyses. Materials 2021, 14, 5459. [CrossRef]

20. Kaur, G.; Singari, R.M.; Kumar, H. A review of fused filament fabrication (FFF): Process parameters and their impact on the tribological behavior of polymers (ABS). Mater. Today Proc. 2021. [CrossRef]

21. Norani, M.N.M.; Abdollah, M.F.B.; Abdullah, M.I.H.C.; Amiruddin, H.; Ramli, F.R.; Tamaldin, N. Correlation of tribo-mechanical properties of internal geometry structures of fused filament fabrication 3D-printed acrylonitrile butadiene styrene. Ind. Lubr. Tribol. 2020, 72, 1259-1265. [CrossRef]

22. Hanon, M.M.; Kovács, M.; Zsidai, L. Tribology behaviour investigation of 3D printed polymers. Int. Rev. Appl. Sci. Eng. 2019, 10, 173-181. [CrossRef]

23. Prabhu, R.; Devaraju, A. Recent review of tribology, rheology of biodegradable and FDM compatible polymers. Mater. Today Proc. 2021, 39, 781-788. [CrossRef]

24. Amirruddin, M.S.; Ismail, K.I.; Yap, T.C. Effect of layer thickness and raster angle on the tribological behavior of 3D printed materials. Mater. Today Proc. 2021. [CrossRef]

25. Arif, M.F.; Alhashmi, H.; Varadarajan, K.M.; Koo, J.H.; Hart, A.J.; Kumar, S. Multifunctional performance of carbon nanotubes and graphene nanoplatelets reinforced PEEK composites enabled via FFF additive manufacturing. Compos. Part B Eng. 2020, $184,107625$. [CrossRef]

26. Conference, I.; Pawlak, W. Wear and coefficient of friction of pla-graphite composite in 3D printing technology. Eng. Mech. 2018, 2018, 649-652. [CrossRef]

27. Pawlak, W.; Kowalewski, P.; Przekop, R. On the tribological properties of polylactide (PLA) applied in 3D printing technology. Tribologia 2020, 289, 57-62. [CrossRef]

28. Ladipo, T.L.; Masu, L.; Nziu, P. Solid Additives and their Lubrication Effects on Polyetheretherketone Polymers-A Review. Int. J. Eng. Res. Technol. 2020, 13, 4262-4268.

29. Da Silva, D.; Kaduri, M.; Poley, M.; Adir, O.; Krinsky, N.; Shainsky-Roitman, J.; Schroeder, A. Biocompatibility, biodegradation and excretion of polylactic acid (PLA) in medical implants and theranostic systems. Chem. Eng. J. 2018, 340, 9-14. [CrossRef]

30. Arif, M.F.; Kumar, S.; Varadarajan, K.M.; Cantwell, W.J. Performance of biocompatible PEEK processed by fused deposition additive manufacturing. Mater. Des. 2018, 146, 249-259. [CrossRef]

31. Wu, H.; Fahy, W.P.; Kim, S.; Kim, H.; Zhao, N.; Pilato, L.; Kafi, A.; Bateman, S.; Koo, J.H. Recent developments in polymers/polymer nanocomposites for additive manufacturing. Prog. Mater. Sci. 2020, 111, 100638. [CrossRef]

32. Zhang, X.; Chen, K.; Xu, L.; Qi, J.; Luo, Y.; Zhang, D. Tribological behavior of Ti6Al4 V alloy swing against UHMWPE under different lubrication. J. Thermoplast. Compos. Mater. 2019. [CrossRef]

33. Wang, C.; Zhang, G.; Li, Z.; Zeng, X.; Xu, Y.; Zhao, S.; Hu, H.; Zhang, Y.; Ren, T. Tribological behavior of Ti-6Al-4V against cortical bone in different biolubricants. J. Mech. Behav. Biomed. Mater. 2019, 90, 460-471. [CrossRef] [PubMed]

34. Nithyaprakash, R.; Shankar, S.; Santhosh, B.R.; Kumar, T.K.; Kiruba, P.; Srinivas, K.M. Tribological behavior of polyethylene and ceramic biomaterials under different bio-lubricants. Trends Biomater. Artif. Organs 2021, 35, 44-47.

35. Araujo Borges, R.; Choudhury, D.; Zou, M. 3D printed PCU/UHMWPE polymeric blend for artificial knee meniscus. Tribol. Int. 2018, 122, 1-7. [CrossRef]

36. Wang, X.; Zhao, L.; Fuh, J.Y.H.; Lee, H.P. Effect of Porosity on Mechanical Properties of 3D Printed Polymers: Experiments and Micromechanical Modeling Based on X-ray Computed Tomography Analysis. Polymers 2019, 11, 1154. [CrossRef] [PubMed]

37. Buj-Corral, I.; Bagheri, A.; Sivatte-Adroer, M. Effect of Printing Parameters on Dimensional Error, Surface Roughness and Porosity of FFF Printed Parts with Grid Structure. Polymers 2021, 13, 1213. [CrossRef]

38. Von Windheim, N.; Collinson, D.W.; Lau, T.; Brinson, L.C.; Gall, K. The influence of porosity, crystallinity and interlayer adhesion on the tensile strength of 3D printed polylactic acid (PLA). Rapid Prototyp. J. 2021, 27, 1327-1336. [CrossRef]

39. Abar, B.; Alonso-Calleja, A.; Kelly, A.; Kelly, C.; Gall, K.; West, J.L. 3D printing of high-strength, porous, elastomeric structures to promote tissue integration of implants. J. Biomed. Mater. Res. Part A 2021, 109, 54-63. [CrossRef]

40. Seok, J.M.; Rajangam, T.; Jeong, J.E.; Cheong, S.; Joo, S.M.; Oh, S.J.; Shin, H.; Kim, S.-H.; Park, S.A. Fabrication of 3D plotted scaffold with microporous strands for bone tissue engineering. J. Mater. Chem. B 2020, 8, 951-960. [CrossRef] [PubMed]

41. Zhou, X.; Feng, Y.; Zhang, J.; Shi, Y.; Wang, L. Recent advances in additive manufacturing technology for bone tissue engineering scaffolds. Int. J. Adv. Manuf. Technol. 2020, 108, 3591-3606. [CrossRef]

42. Luis, E.; Pan, H.M.; Bastola, A.K.; Bajpai, R.; Sing, S.L.; Song, J.; Yeong, W.Y. 3D printed silicone meniscus implants: Influence of the $3 \mathrm{D}$ printing process on properties of silicone implants. Polymers 2020, 12, 2136. [CrossRef]

43. Masood, S.H.; Song, W.Q. Development of new metal/polymer materials for rapid tooling using Fused deposition modelling. Mater. Des. 2004, 25, 587-594. [CrossRef]

44. Lambiase, F.; Di Ilio, A. Mechanical clinching of metal-polymer joints. J. Mater. Process. Technol. 2015, 215, 12-19. [CrossRef]

45. Carradò, A.; Faerber, J.; Niemeyer, S.; Ziegmann, G.; Palkowski, H. Metal/polymer/metal hybrid systems: Towards potential formability applications. Compos. Struct. 2011, 93, 715-721. [CrossRef]

46. Lambiase, F.; Scipioni, S.I.; Lee, C.J.; Ko, D.C.; Liu, F. A state-of-the-art review on advanced joining processes for metal-composite and metal-polymer hybrid structures. Materials 2021, 14, 1890. [CrossRef] 
47. Lambiase, F.; Grossi, V.; Paoletti, A. High-speed joining of hybrid metal-polymer joints during the friction-assisted joining process. Compos. Struct. 2022, 280, 114890. [CrossRef]

48. Bula, K.; Sterzyński, T.; Piasecka, M.; Rózański, L. Deformation mechanism in mechanically coupled polymer-metal hybrid joints. Materials 2020, 13, 2512. [CrossRef]

49. Ghiya, R.; Badheka, V.J. A review of friction stir lap welding of polymer to metal. Polym. Technol. Mater. 2021, 60, 1966-1995. [CrossRef]

50. Liu, F.C.; Dong, P.; Pei, X. A high-speed metal-to-polymer direct joining technique and underlying bonding mechanisms. J. Mater. Process. Technol. 2020, 280, 116610. [CrossRef]

51. Ozlati, A.; Movahedi, M.; Tamizi, M.; Tartifzadeh, Z.; Alipour, S. An alternative additive manufacturing-based joining method to make Metal/Polymer hybrid structures. J. Manuf. Process. 2019, 45, 217-226. [CrossRef]

52. Zou, X.; Huang, L.; Chen, K.; Jiang, M.; Zhang, S.; Wang, M.; Hua, X.; Shan, A. Surface structuring via additive manufacturing to improve the performance of metal and polymer joints. Metals 2021, 11, 567. [CrossRef]

53. Siemiński, P.; Budzik, G. Techniki Przyrostowe. Druk 3D. Drukarki 3D; Oficyna Wydawnicza Politechniki Warszawskiej: Warsaw, Poland, 2015.

54. Rahim, T.N.A.T.; Abdullah, A.M.; Akil, H. Recent Developments in Fused Deposition Modeling-Based 3D Printing of Polymers and Their Composites. Polym. Rev. 2019, 59, 589-624. [CrossRef]

55. Cui, C.; Hu, B.; Zhao, L.; Liu, S. Titanium alloy production technology, market prospects and industry development. Mater. Des. 2011, 32, 1684-1691. [CrossRef]

56. Moiduddin, K.; Mian, S.H.; Umer, U.; Alkhalefah, H. Fabrication and Analysis of a Ti6Al4V Implant for Cranial Restoration. Appl. Sci. 2019, 9, 2513. [CrossRef]

57. Al Kindi, M.N.; Moiduddin, K.; Al-Ahmari, A.; Nasr, E.S.A.; Ramalingam, S.; Badwelan, M. Functional and aesthetic outcomes of electron beam-melted titanium reconstruction plates: An in vivo goat study. Biomed. Res. 2017, 28, 2073-2080.

58. Lee, J.-W.; Fang, J.-J.; Chang, L.-R.; Yu, C.-K. Mandibular Defect Reconstruction with the Help of Mirror Imaging Coupled with Laser Stereolithographic Modeling Technique. J. Formos. Med. Assoc. 2007, 106, 244-250. [CrossRef]

59. Nath, S.D.; Nilufar, S. An Overview of Additive Manufacturing of Polymers and Associated Composites. Polymers 2020, 12, 2719. [CrossRef]

60. Przekop, R.E.; Kujawa, M.; Pawlak, W.; Dobrosielska, M.; Sztorch, B.; Wieleba, W. Graphite Modified Polylactide (PLA) for 3D Printed (FDM/FFF) Sliding Elements. Polymers 2020, 12, 1250. [CrossRef]

61. Singh, D.; Singh, R.; Boparai, K.S. Development and surface improvement of FDM pattern based investment casting of biomedical implants: A state of art review. J. Manuf. Process. 2018, 31, 80-95. [CrossRef]

62. Schirmeister, C.G.; Hees, T.; Licht, E.H.; Mülhaupt, R. 3D printing of high density polyethylene by fused filament fabrication Addit. Manuf. 2019, 28, 152-159. [CrossRef]

63. Wong, K.C. 3D-printed patient-specific applications in orthopedics. Orthop. Res. Rev. 2016, 8, 57-66. [CrossRef]

64. Khalil, Y.; Hopkinson, N.; Kowalski, A.; Fairclough, J.P.A. Characterisation of UHMWPE polymer powder for laser sintering. Materials 2019, 12, 3496. [CrossRef] [PubMed]

65. Z-PLA Technical Data Sheet. Available online: https://cf.zortrax.com/wp-content/uploads/2018/06/Z-PLA_Technical_Data_ Sheet_eng-1.pdf (accessed on 10 November 2021).

66. Z-NYLON Technical Data Sheet. Available online: https://cf.zortrax.com/wp-content/uploads/2018/11/Z-NYLON_Technical_ Data_Sheet_eng-2.pdf (accessed on 10 November 2021).

67. Kujawa, M. The influence of first layer parameters on adhesion between the 3D printer's glass bed and ABS. In Interdyscyplinarność Badań Naukowych; Oficyna Wydawnicza Politechniki Wrocławskiej: Wrocław, Poland, 2017; pp. 76-81.

68. Zhu, K.; Deng, Z.; Dai, S.; Yu, Y. Temperature-compensated constitutive model of fused filament fabrication 3D printed PLA materials with full extrusion temperatures. Rapid Prototyp. J. 2021, 28, 41-51. [CrossRef]

69. Vanaei, H.R.; Shirinbayan, M.; Vanaei, S.; Fitoussi, J.; Khelladi, S.; Tcharkhtchi, A. Multi-scale damage analysis and fatigue behavior of PLA manufactured by fused deposition modeling (FDM). Rapid Prototyp. J. 2021, 27, 371-378. [CrossRef]

70. Arifvianto, B.; Wirawan, Y.B.; Salim, U.A.; Suyitno, S.; Mahardika, M. Effects of extruder temperatures and raster orientations on mechanical properties of the FFF-processed polylactic-acid (PLA) material. Rapid Prototyp. J. 2021, 27, 1761-1775. [CrossRef]

71. Calignano, F.; Lorusso, M.; Roppolo, I.; Minetola, P. Investigation of the Mechanical Properties of a Carbon Fibre-Reinforced Nylon Filament for 3D Printing. Machines 2020, 8, 52. [CrossRef]

72. El Magri, A.; Vanaei, S.; Shirinbayan, M.; Vaudreuil, S.; Tcharkhtchi, A. An Investigation to Study the Effect of Process Parameters on the Strength and Fatigue Behavior of 3D-Printed PLA-Graphene. Polymers 2021, 13, 3218. [CrossRef]

73. Vanaei, H.R.; Shirinbayan, M.; Deligant, M.; Khelladi, S.; Tcharkhtchi, A. In-Process Monitoring of Temperature Evolution during Fused Filament Fabrication: A Journey from Numerical to Experimental Approaches. Thermo 2021, 1, 332-360. [CrossRef]

74. Kuznetsov, V.; Solonin, A.; Urzhumtsev, O.; Schilling, R.; Tavitov, A. Strength of PLA Components Fabricated with Fused Deposition Technology Using a Desktop 3D Printer as a Function of Geometrical Parameters of the Process. Polymers $2018,10,313$. [CrossRef]

75. Hsueh, M.-H.; Lai, C.-J.; Chung, C.-F.; Wang, S.-H.; Huang, W.-C.; Pan, C.-Y.; Zeng, Y.-S.; Hsieh, C.-H. Effect of Printing Parameters on the Tensile Properties of 3D-Printed Polylactic Acid (PLA) Based on Fused Deposition Modeling. Polymers 2021, $13,2387$. [CrossRef] 
76. Tate, J.S.; Brushaber, R.P.; Danielsen, E.; Kallagunta, H.; Navale, S.V.; Arigbabowo, O.; Shree, S.; Yaseer, A. Electrical and mechancial properties of fused filament fabrication of polyamide 6/nanographene filaments at different annealing temperatures. In Proceedings of the 30th Annual International Solid Freeform Fabrication Symposium-An Additive Manufacturing Conference, Austin, TX, USA, 12-14 August 2019; pp. 1008-1021. Available online: https://utw10945.utweb.utexas.edu/sites/default/files/ 2019/088\%20Electrical\%20and\%20Mechancial\%20Properties\%20of\%20Fused\%20Fila.pdf (accessed on 10 November 2021).

77. Abdullah, A.M.; Tuan Rahim, T.N.A.; Mohamad, D.; Akil, H.M.; Rajion, Z.A. Mechanical and physical properties of highly ZrO2 $/ \beta$-TCP filled polyamide 12 prepared via fused deposition modelling (FDM) 3D printer for potential craniofacial reconstruction application. Mater. Lett. 2017, 189, 307-309. [CrossRef]

78. Jordá-Vilaplana, A.; Fombuena, V.; García-García, D.; Samper, M.D.; Sánchez-Nácher, L. Surface modification of polylactic acid (PLA) by air atmospheric plasma treatment. Eur. Polym. J. 2014, 58, 23-33. [CrossRef]

79. Novák, I.; Števiar, M.; Chodák, I. Surface Energy and Adhesive Properties of Polyamide 12 Modified by Barrier and RadioFrequency Discharge Plasma. Mon. Chem.-Chem. Mon. 2006, 137, 943-952. [CrossRef]

80. McNally, T.; Raymond Murphy, W.; Lew, C.Y.; Turner, R.J.; Brennan, G.P. Polyamide-12 layered silicate nanocomposites by melt blending. Polymer 2003, 44, 2761-2772. [CrossRef]

81. Lim, L.-T.; Auras, R.; Rubino, M. Processing technologies for poly(lactic acid). Prog. Polym. Sci. 2008, 33, 820-852. [CrossRef]

82. Lay, M.; Thajudin, N.L.N.; Hamid, Z.A.A.; Rusli, A.; Abdullah, M.K.; Shuib, R.K. Comparison of physical and mechanical properties of PLA, ABS and nylon 6 fabricated using fused deposition modeling and injection molding. Compos. Part B Eng. 2019, 176, 107341. [CrossRef]

83. Godec, D.; Cano, S.; Holzer, C.; Gonzalez-Gutierrez, J. Optimization of the 3D Printing Parameters for Tensile Properties of Specimens Produced by Fused Filament Fabrication of 17-4PH Stainless Steel. Materials 2020, 13, 774. [CrossRef]

84. Bochnia, J.; Blasiak, M.; Kozior, T. A Comparative Study of the Mechanical Properties of FDM 3D Prints Made of PLA and Carbon Fiber-Reinforced PLA for Thin-Walled Applications. Materials 2021, 14, 7062. [CrossRef]

85. Yan, R.; Wang, Y.; Luo, P.; Li, Y.; Lu, X. Fused filament fabrication of continuous optic fiber reinforced polylactic acid composites. Rapid Prototyp. J. 2021. [CrossRef]

86. Sobociński, M. Analysis of friction and lubrication of human joint's surfaces. J. Appl. Math. Comput. Mech. 2016, 15, 161-167. [CrossRef]

87. Okolie, O.; Stachurek, I.; Kandasubramanian, B.; Njuguna, J. 3D Printing for Hip Implant Applications: A Review. Polymers 2020, 12, 2682. [CrossRef] [PubMed]

88. Terekhina, S.; Tarasova, T.; Egorov, S.; Guillaumat, L.; Hattali, M.L. On the difference in material structure and fatigue properties of polyamide specimens produced by fused filament fabrication and selective laser sintering. Int. J. Adv. Manuf. Technol. 2020, 111, 93-107. [CrossRef]

89. Liao, Y.; Liu, C.; Coppola, B.; Barra, G.; Di Maio, L.; Incarnato, L.; Lafdi, K. Effect of Porosity and Crystallinity on 3D Printed PLA Properties. Polymers 2019, 11, 1487. [CrossRef] [PubMed]

90. Al-Maharma, A.Y.; Patil, S.P.; Markert, B. Effects of porosity on the mechanical properties of additively manufactured components: A critical review. Mater. Res. Express 2020, 7, 122001. [CrossRef] 